\title{
The X-43A Hyper-X Mach 7 Flight 2 Guidance, Navigation, and Control Overview and Flight Test Results
}

\author{
Catherine Bahm, ${ }^{*}$ Ethan Baumann, ${ }^{\dagger}$ \\ NASA Dryden Flight Research Center, Edwards, California, 93523 \\ John Martin, \\ NASA Langley Research Center, Hampton, Virginia, 23681 \\ David Bose ${ }^{\S}$ Roger E. Beck, ${ }^{* *}$ and Brian Strovers ${ }^{\dagger \dagger}$ \\ Analytical Mechanics Associates, Inc., Hampton, Virginia, 23666
}

\begin{abstract}
The objective of the Hyper-X program was to flight demonstrate an airframe-integrated hypersonic vehicle. On March 27, 2004, the Hyper-X program team successfully conducted flight 2 and achieved all of the research objectives. The Hyper-X research vehicle successfully separated from the Hyper-X launch vehicle and achieved the desired engine test conditions before the experiment began. The research vehicle rejected the disturbances caused by the cowl door opening and the fuel turning on and off and maintained the engine test conditions throughout the experiment. After the engine test was complete, the vehicle recovered and descended along a trajectory while performing research maneuvers. The last data acquired showed that the vehicle maintained control to the water. This report will provide an overview of the research vehicle guidance and control systems and the performance of the vehicle during the separation event and engine test. The research maneuvers were performed to collect data for aerodynamics and flight controls research. This report also will provide an overview of the flight controls related research and results.
\end{abstract}

$\begin{array}{ll}\text { AMW } & \text { all moving wing } \\ \text { ARI } & \text { aileron-to-rudder interconnect } \\ \text { deg } & \text { degree } \\ \text { FADS } & \text { flush airdata sensing } \\ \text { FFT } & \text { Fast Fourier Transform } \\ \text { fps } & \text { feet per second } \\ \text { ft } & \text { feet } \\ \text { GNC } & \text { guidance, navigation, and control } \\ \text { HXLV } & \text { Hyper-X launch vehicle } \\ \text { HXRV } & \text { Hyper-X research vehicle (X-43A) }\end{array}$

\section{Nomenclature}

${ }^{*}$ Aerospace Engineer, P.O. Box 273/MS 4840D.

'Aerospace Engineer, P.O. Box 273/MS 4840D.

* Aerospace Engineer, 100 NASA Road/MS 451.

$\S$ Aerospace Engineer, 303 Butler Farm Rd Ste 104a.

${ }^{* *}$ Aerospace Engineer, 303 Butler Farm Rd Ste 104a.

${ }^{\dagger}$ Aerospace Engineer, PO Box 273/MS 4840H. 


\begin{tabular}{|c|c|}
\hline$K_{\text {ari }}$ & ARI gain \\
\hline $\mathrm{kft}$ & thousand feet \\
\hline$K_{\mathrm{i}}$ & integrator gain \\
\hline$K_{\mathrm{P}}$ & roll rate gain \\
\hline$K_{\mathrm{p}}$ & proportional angle of attack error gain \\
\hline$K_{\text {phi }}$ & proportional bank angle error gain \\
\hline$K_{\mathrm{q}}$ & pitch rate gain \\
\hline$K_{\mathrm{r}}$ & yaw rate gain \\
\hline MDL & mission data load \\
\hline MIB & Mishap Investigation Board \\
\hline $\mathrm{ms}$ & millisecond(s) \\
\hline $\mathrm{nmi}$ & nautical miles \\
\hline$n_{\mathrm{z}}$ & normal acceleration \\
\hline$n_{\mathrm{zcmd}}$ & normal acceleration command \\
\hline PID & parameter identification \\
\hline POPU & push-over pull-up \\
\hline PSC & propulsion system control \\
\hline psf & pounds per square foot \\
\hline RTF & return to flight \\
\hline s & second(s), time \\
\hline$q_{b a r}$ & dynamic pressure, psf \\
\hline $\mathrm{X}_{\mathrm{sep}}$ & separation distance, in \\
\hline$\alpha$ & angle of attack, deg \\
\hline$\alpha \hat{c o m}$ & equivalent angle of attack command, deg \\
\hline$\alpha_{\text {com }}$ & angle of attack command, deg \\
\hline$\beta$ & sideslip angle, deg \\
\hline$\phi$ & bank angle, deg \\
\hline$\phi_{\mathrm{cmd}}$ & bank angle command, deg \\
\hline
\end{tabular}

\section{Introduction}

$\mathrm{T}$ HE Hyper-X program was the first ever flight demonstration of an airframe-integrated, scramjet-powered, hypersonic vehicle. The objective of the program was to demonstrate and validate the tools, test and analysis techniques, and design methodologies of scramjet-powered hypersonic vehicles. ${ }^{1}$ The guidance and flight controls were needed for the success of the propulsion experiment. The research vehicle flight controls and guidance were required to reject the disturbance caused by separation from the launch vehicle, maintain the engine test flight conditions, and remain controlled during the descent while performing additional research maneuvers. These requirements were successfully executed during the Mach 7 flight 2 on March 27, 2004. This report will provide an overview of the Mach 7 flight 2 research vehicle guidance and control systems and the performance of the vehicle during the separation event and engine test. This report will also provide a brief description and results of the additional flight controls research that was performed during the descent. 


\section{Hyper-X Program Overview}

The objective of the Hyper-X program was the in-flight demonstration of an airframe-integrated scramjet. The primary goal of the project was to successfully perform the engine test and gather propulsion and performance data. ${ }^{1}$ The Hyper-X project consisted of three flights to gather data for the scramjet engines that were optimized for specific flight conditions. The first two flights were to occur at Mach 7 and the third flight at Mach 10. The Hyper-X research vehicle (HXRV) (Fig. 1), was an unmanned autonomous vehicle, $12 \mathrm{ft}(3.66 \mathrm{~m})$ in length, $5 \mathrm{ft}(1.52 \mathrm{~m})$ wide, and weighed approximately $3000 \mathrm{lb}(13,345 \mathrm{~N})$. The Alliant Techsystems Inc. - GASL (ATK-GASL) team provided the HXRV and the adapter that connects the HXRV to the launch vehicle. The Hyper-X launch vehicle (HXLV) was a modified Pegasus booster provided by Orbital Sciences Corporation (Chandler, Arizona). Figure 2 shows the nominal flight sequence for the Mach 7 flight 2 mission. The Hyper-X stack, the combined HXLV, HXRV, and adapter (Fig. 3), was carried by the NASA B-52B aircraft to the Western Test Range over the Pacific Ocean off the coast of Southern California of the United States of America. After drop from the B-52B aircraft, the HXLV carried the HXRV to the separation point at a velocity of approximately Mach 7, an altitude of 95,000 ft $(28.96 \mathrm{~km})$, and a dynamic pressure of approximately $1,000 \mathrm{psf}(47.88 \mathrm{kPa})$. The HXRV then separated from the HXLV, stabilized, and achieved the desired engine test conditions within $2.5 \mathrm{~s}$. During the engine test, the HXRV maintained the engine test conditions, collected fuel off performance baseline data during pre- and post-experiment tares of 5 and $4 \mathrm{~s}$, respectively, and conducted the cowl open parameter identification (PID) maneuver. The fueled portion of the engine test lasted approximately $10 \mathrm{~s}$. After the engine test was complete, the HXRV recovered by increasing the angle of attack of the vehicle to arrest the buildup of dynamic pressure and minimize heating. When the recovery maneuver was complete, the HXRV descended along a reference trajectory to an impact location determined based on the flight conditions at separation. Along the descent, the HXRV performed four research maneuver sets to acquire aerodynamic and flight controls research data. The descent research maneuvers included PID maneuvers, flight controls frequency sweeps, and push-over pull-up (POPU) maneuvers. Figure 4 shows an example of the angle of attack response for a descent research maneuver.

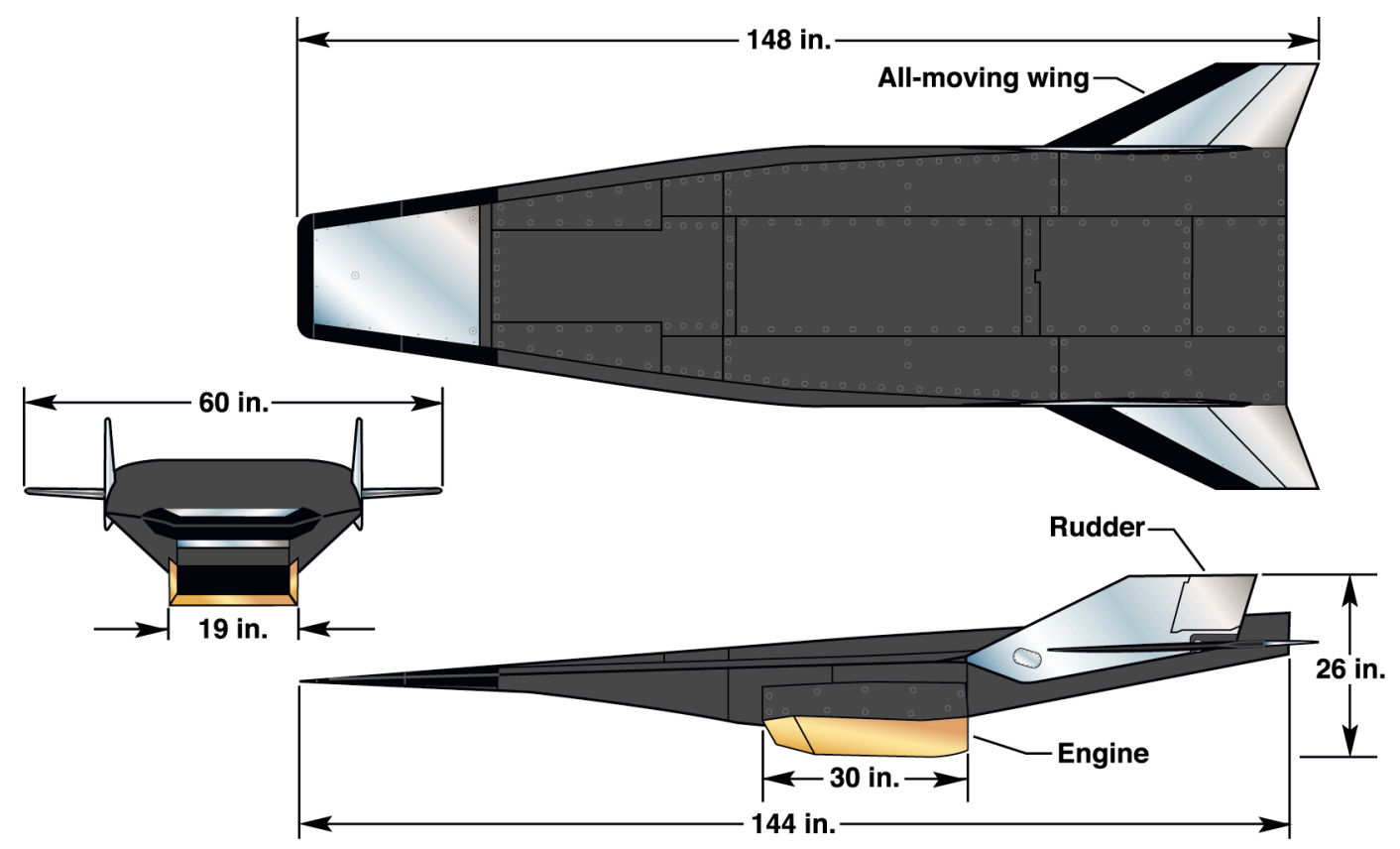

Figure 1. Research vehicle configuration. 


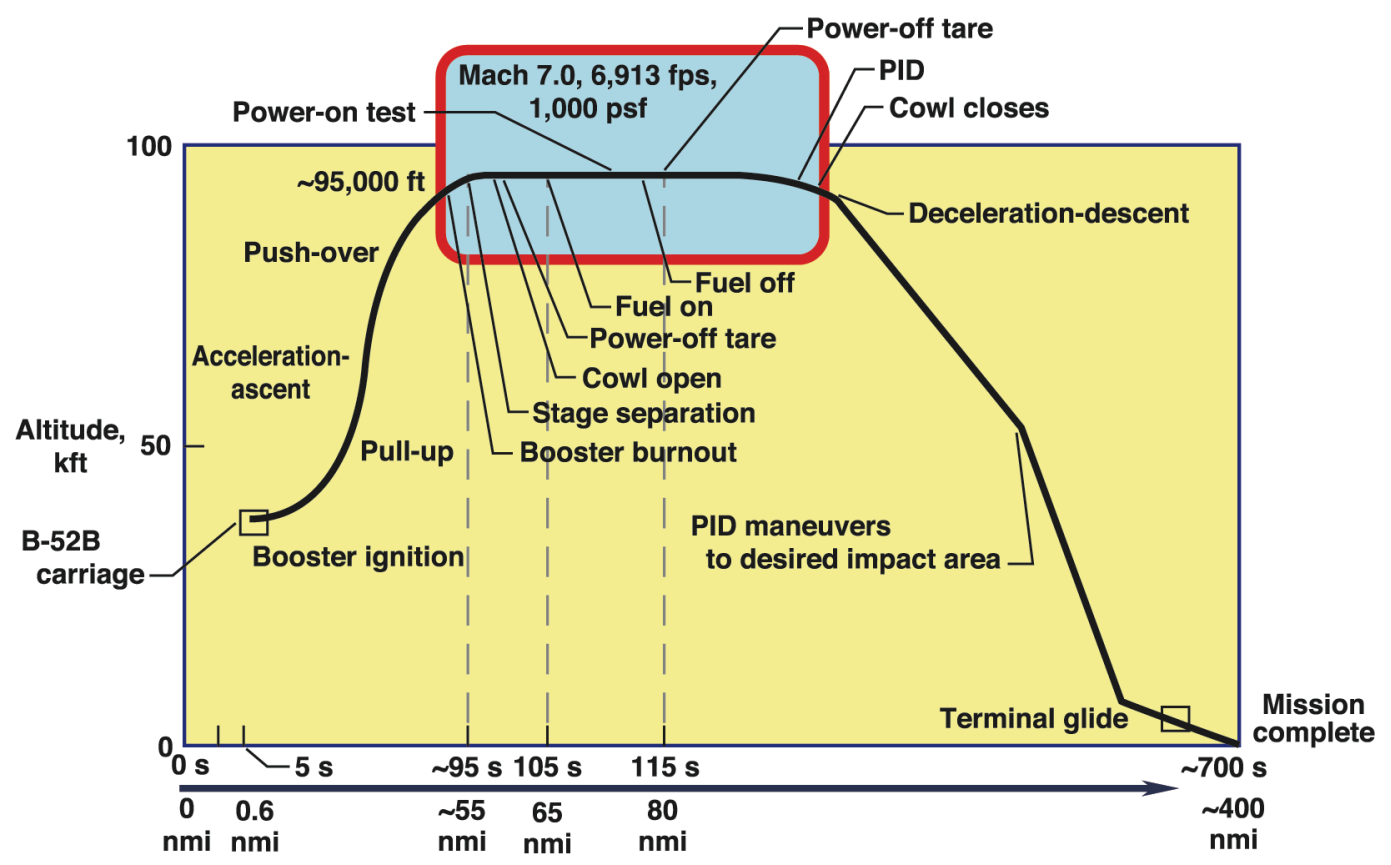

Figure 2. Nominal Mach 7 mission profile.

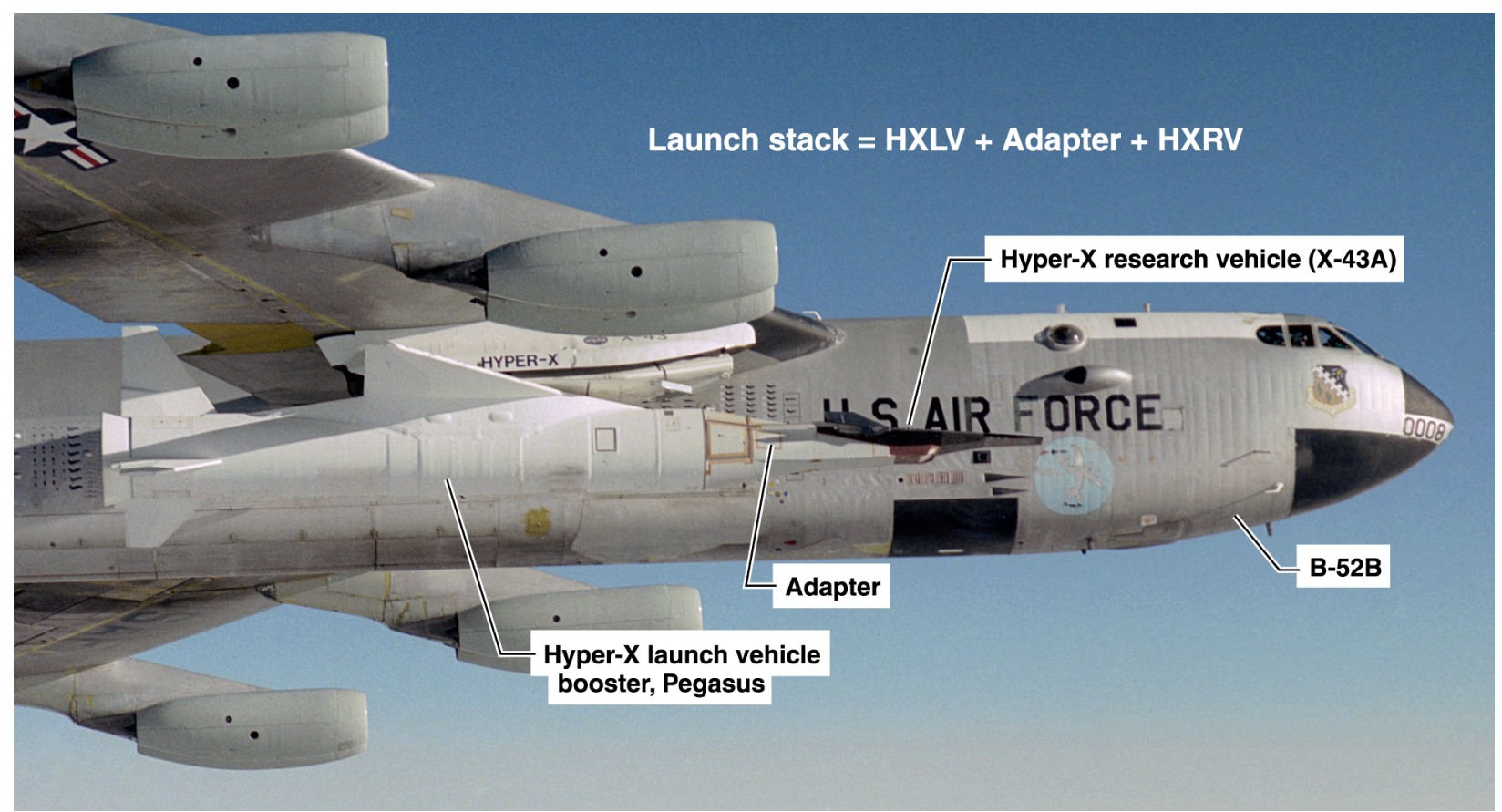

Figure 3. Hyper-X components. 


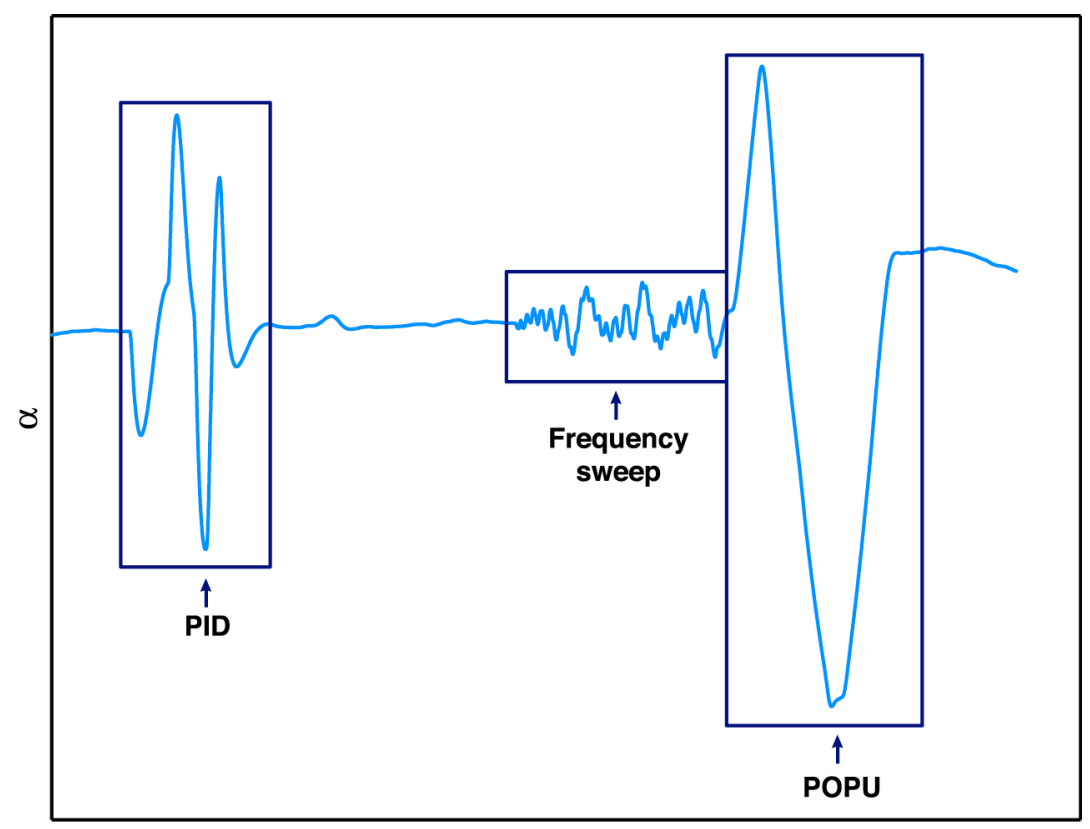

Time

Figure 4. Angle of attack response for descent maneuvers.

\section{Guidance and Flight Control System Description and Requirements}

The HXRV was an unpiloted vehicle with a single string digital flight control system running on a Honeywell flight control computer from the H-764 family of Inertial Navigation System/Global Positioning System (INS/GPS). The HXRV flight control computer was the same as those used on the Navy's Standoff Land Attack Missile-Expanded Response (SLAM-ER) missile. The pure inertial navigation solution was used for all parameters for the Mach 7 HXRV mission with the exception of the angle of attack. During the descent, the inertial angle of attack measurement was augmented with a flush airdata sensing (FADS) estimated angle of attack.

The HXRV guidance routines were hand-coded in ADA and run at a rate of $25 \mathrm{~Hz}$, or a frame update time of $40 \mathrm{~ms}$. The flight control laws were auto-coded in C from Matlab Simulink Block Diagrams and designed to run at a rate of $100 \mathrm{~Hz}$, which provided a frame update time of $10 \mathrm{~ms}$. The HXRV had four aerosurfaces, two rudders, and two all moving wings (AMWs). The rudders moved symmetrically, while the AMWs moved symmetrically and differentially for pitch and roll control, respectively. Symmetric and differential deflections of the AMWs are referred to as elevator and aileron deflections, respectively. An electromechanical actuator (EMA) controlled each surface. Figure 5 shows a block diagram representation of the flight controls and guidance software routines. The flight software also included the propulsion system control (PSC) algorithms. The PSC software was developed by the propulsion team to control the cowl door, hydrogen system, and engine igniter system. ${ }^{2}$ The PSC software also included algorithms to provide unstart protection during the engine experiment; however, this report will not discuss the PSC software or the flight test results of those algorithms.

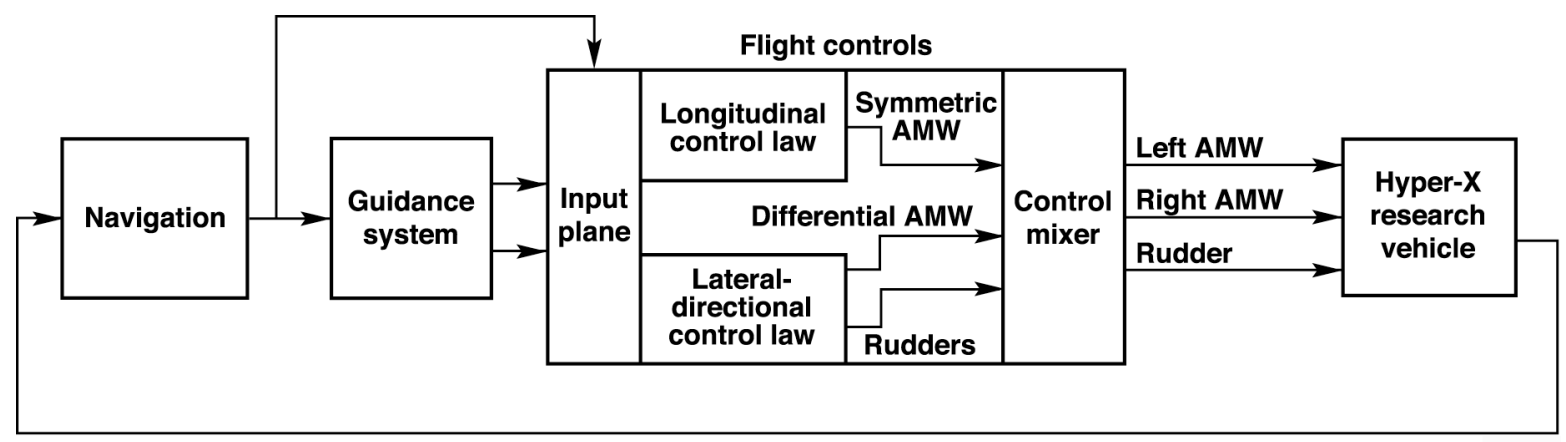

Figure 5. GNC overview block diagram. 
The target flight conditions for the Mach 7 flight 2 engine test were defined as follows: Mach number of $7.0 \pm 0.5$, dynamic pressure of $1000 \pm 200 \mathrm{psf}(47.88 \pm 9.58 \mathrm{kPa})$, sideslip angle of $0 \pm 0.5 \mathrm{deg}(0 \pm 0.0087 \mathrm{rad})$, and nominal angle of attack of $2.5 \mathrm{deg}(0.044 \mathrm{rad})$. An angle of attack of 1.5 to $3.5 \mathrm{deg}(0.026$ to $0.061 \mathrm{rad})$ was acceptable if the inertial angle of attack during the engine test was maintained within $\pm 0.5 \mathrm{deg}(0.0087 \mathrm{rad})$ from cowl open through post engine-on tare. Exceptions to the angle of attack requirement included transient events that consisted of cowl open, engine ignition, engine off, and potential engine unstart. The engine test Mach number and dynamic pressure in flight were highly dependent on the HXLV performance and the conditions at separation. This dependency was caused by the inability of the HXRV to control the Mach number and dynamic pressure during the experiment as a result of the short duration of the separation event and engine test.

To ensure HXRV stability, performance, and robustness, nominal and off-nominal stability and control requirements were defined for all phases of flight. The control system was designed to nominally have a minimum of $6 \mathrm{~dB}$ gain margin and $45 \mathrm{deg}(0.785 \mathrm{rad})$ phase margin for all feedback loops. Linear Monte Carlo dispersed cases were required to have a minimum of $3 \mathrm{~dB}$ gain margin and $20 \mathrm{deg}(0.349 \mathrm{rad})$ phase margin from separation through cowl closed and to remain stable (positive gain and phase margins) through the recovery maneuver and descent. The structural mode suppression was required to be greater than $9 \mathrm{~dB}$ and all closed-loop eigenvalues were required to have damping ratios greater than 0.2 . The post-cowl closed controlled descent was not required to meet project primary success criteria. Nonetheless, the post-cowl closed flight control system was designed around goals to increase the probability of successfully completing the additional research objectives.

\section{A. Separation Control Logic}

The separation event occurs during a period of $2.5 \mathrm{~s}$. At the end of this time, the HXRV has separated from the HXLV, rejected the disturbance caused by separation, and acquired the desired engine test conditions. Figure 6 shows the separation event in detail. The separation control elements were designed to initialize the controller, minimize the probability of re-contact with the HXLV, and ensure the robustness of the HXRV to recover from the upset caused by separation. The control system engaged in stages to prevent maneuvering commands from disturbing the HXRV during the separation event. The initial elevator position bias for the separation event was preset and defined in the mission data load (MDL). The MDL capability provided the ability to upload selected HXRV flight control, navigation, and propulsion parameters that were used during the mission by the Operational Flight Program (OFP). At $100 \mathrm{~ms}$ from the start of separation, the inner loops, roll and pitch rate feedbacks, were engaged. The yaw rate feedback began fading in at $400 \mathrm{~ms}$ following separation and was faded in linearly over $600 \mathrm{~ms}$. At $500 \mathrm{~ms}$ after separation, the outer loops, angle of attack and bank angle feedbacks, were engaged.

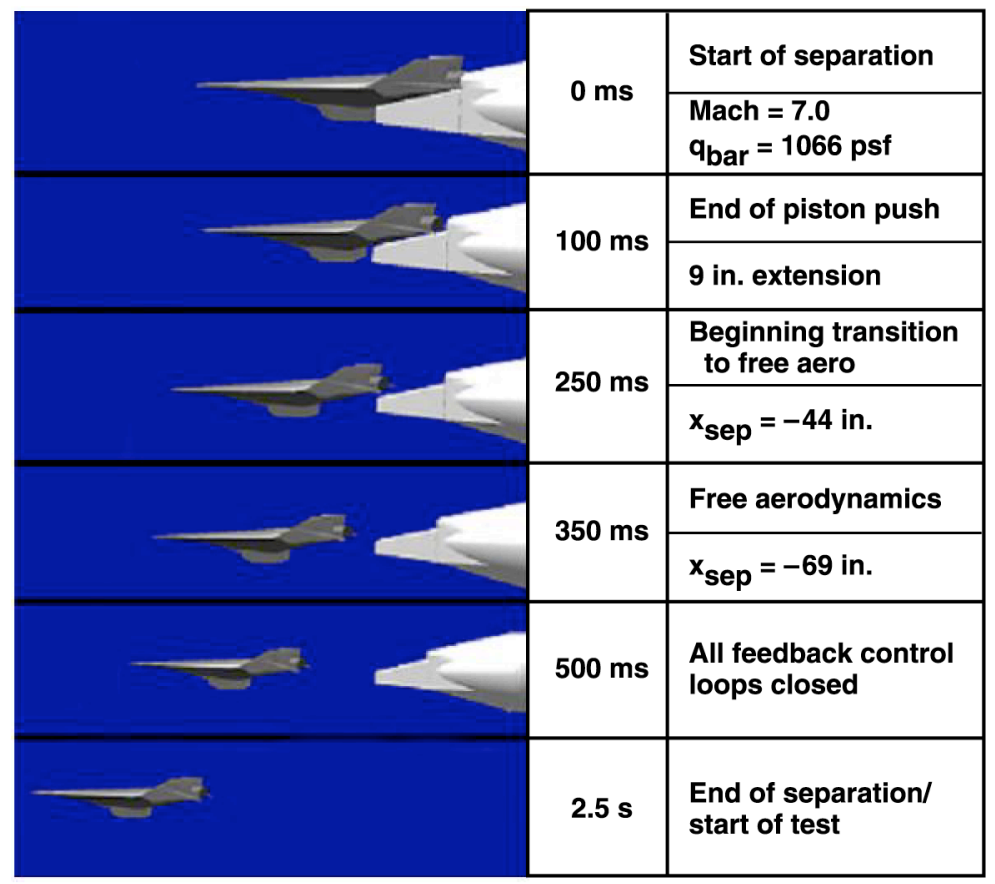

Figure 6. Nominal separation scenario. 


\section{B. Guidance}

The HXRV guidance was an adaptation of space shuttle heritage code. The guidance was modified to account for the HXRV configuration, trajectory, and research objectives. During the engine test, guidance only commanded the desired angle of attack and a zero bank angle. After the cowl door was closed, guidance initiated the recovery maneuver to arrest the buildup of dynamic pressure and vehicle heating. When the rate of descent of the HXRV had been arrested, the guidance transitioned to the descent mode. At that point, bank angle and normal acceleration commands were issued to fly along a reference trajectory to a splash point that was calculated based on the separation conditions. Limits on the angle of attack, dynamic pressure, and normal acceleration were applied to the commands issued from guidance. When the HXRV was at 10,000 $\mathrm{ft}(3.048 \mathrm{~km})$, guidance transitioned to an "approach mode" where a constant flight path angle was commanded.

\section{Longitudinal Controller}

Scramjet performance is highly dependent upon the angle of attack. Therefore during the engine test phase of the flight, the longitudinal controller regulated angle of attack. The control system used inertial angle of attack and body-axis pitch rate arranged in a classical loop structure (Fig. 7). ${ }^{3}$ The longitudinal controller was designed by sequential loop closure (root locus) method. The gain parameters were scheduled as a function of Mach and angle of attack with dynamic pressure compensation. Feedforward elements were incorporated in the longitudinal control system to minimize the effect of known disturbances such as the engine cowl door opening, engine ignition, and fuel off. The longitudinal controller also contained a feedforward on commanded angle of attack to provide an estimate of the elevator trim. The alpha controller was designed to maximize both stability and performance.

Two and one-half seconds after the engine cowl door closed, the controller transitioned to a normal acceleration command controller and remained in this mode throughout the descent. The HXRV guidance, an adaptation of shuttle heritage algorithms, issued normal acceleration commands during the descent. Instead of requiring further modifications to the guidance algorithms, a normal acceleration controller was developed. Desired and actual normal acceleration were used to generate a software limited equivalent angle of attack command that was passed to the alpha controller. Figure 7 shows the normal acceleration controller. The normal acceleration command controller had only one feedforward element, which was commanded angle of attack, to provide an estimate of the elevator trim. After the engine cowl door closed, the inertial angle of attack measurement was augmented with a FADS-estimated angle of attack. The normal acceleration controller was designed to maximize stability while providing acceptable performance.

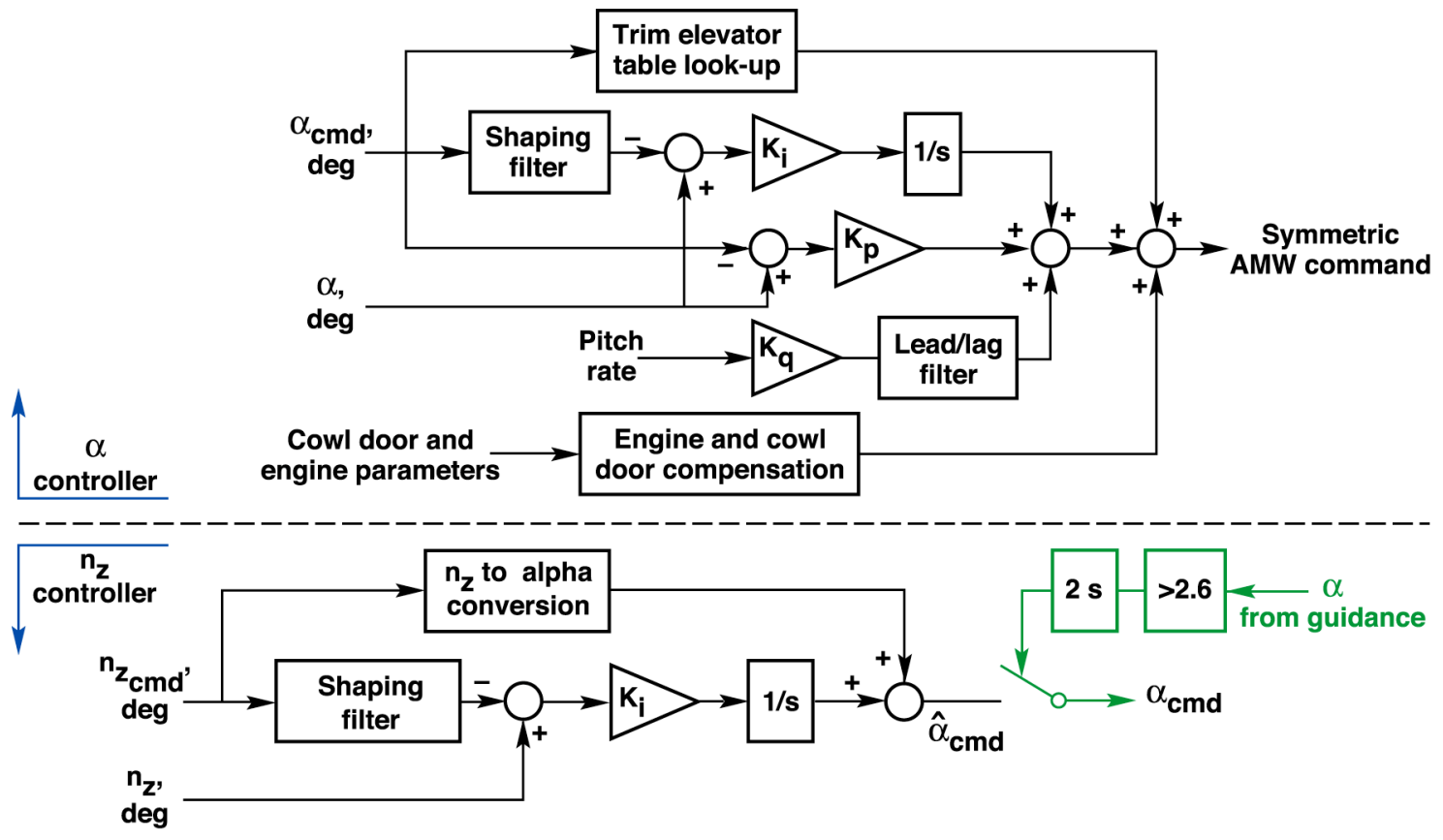

Figure 7. Longitudinal flight controller for engine test and descent phases. 


\section{Lateral-Directional Controller}

The lateral-directional controller regulated bank angle and body-axis roll rate arranged in a classical loop structure (Fig. 8). ${ }^{3}$ Stability-axis yaw rate feedback was regulated to minimize sideslip angle. An aileron-to-rudder interconnect (ARI) was utilized to provide coordinated maneuvers. Unlike the longitudinal controller, the lateral-directional controller was the same structure throughout the flight. Like the longitudinal controller, the lateral-directional controller was designed by sequential loop closure (root locus) method. The controller gain schedules were a function of Mach and angle of attack with dynamic pressure compensation. In the design of the lateral-directional axes, greater emphasis was placed on stability rather than performance.

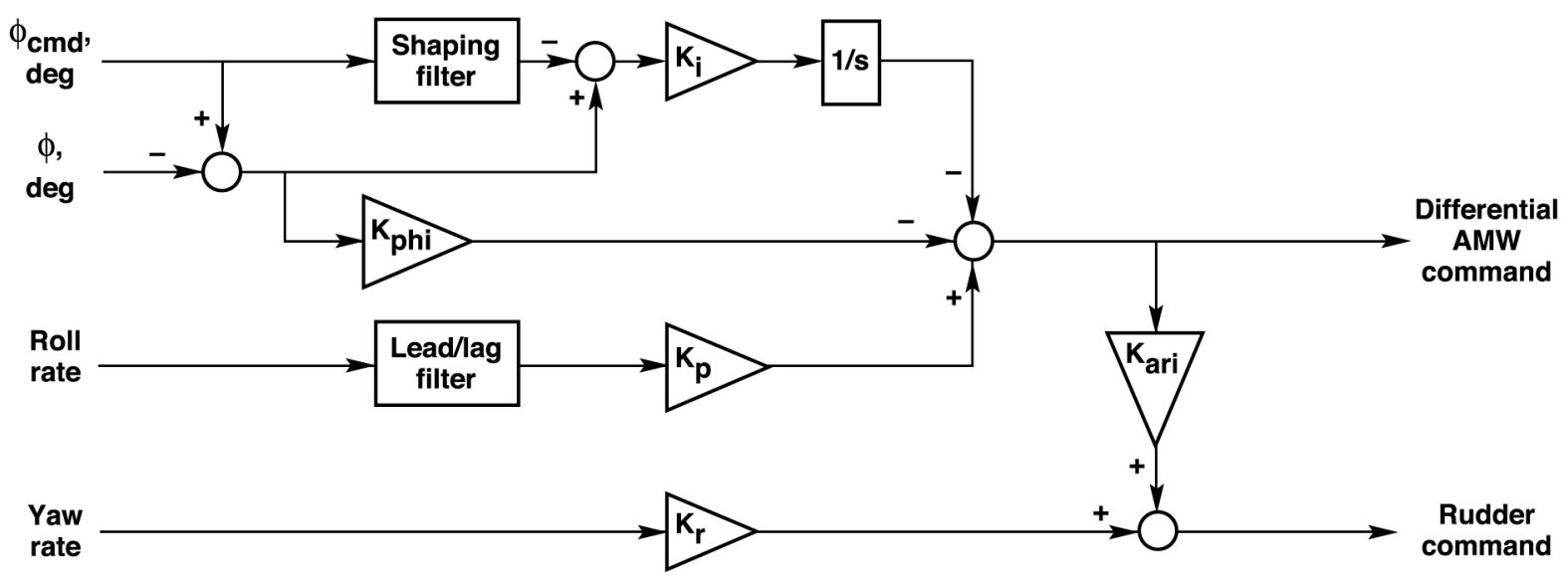

Figure 8. Lateral-Directional flight controller.

\section{Flight 1 and Return to Flight Overview}

The first flight of the Hyper-X vehicle occurred on June 2, 2001. At approximately $13 \mathrm{~s}$ after drop from the B-52 aircraft, the HXLV stack departed from controlled flight. A Mishap Investigation Board (MIB) was convened immediately following the accident. The MIB determined that the "HXLV failed because the vehicle control system design was deficient for the trajectory flown due to inaccurate analytical models." ${ }^{4}$ The HXLV modeling deficiencies caused an over-prediction of the autopilot stability margins.

The return to flight (RTF) effort began in March 2002. The RTF team used the MIB report and corrective actions that were developed in response to the MIB findings as a starting point to develop the RTF plan. ${ }^{5}$ Although a significant part of the RTF plan focused on the lessons learned from flight 1, the ultimate goal of the RTF effort was to reduce risk in all phases of flight. Therefore, the project initiated a review of all phases of flight to identify risks and actions that would mitigate the identified risks.

The risks identified by the flight controls team for the separation, engine test, and descent phases of flight were categorized in the following three areas.

- Robustness of the HXRV flight controls during the separation event, engine test, and descent phases in the presence of disturbances, uncertainties, and unmodeled dynamics. Incorrect prediction of the performance of the vehicle could result in re-contact during separation, non-optimal engine operating conditions, or even vehicle departure.

- Adequacy of the vehicle simulations to fully capture vehicle dynamics. Inaccurate models or simulation errors could impact the accuracy of the simulation and provide optimistic predictions of performance.

- Inaccurate modeling of the vehicle systems that could lead to misprediction of the performance of the vehicle.

The following mitigations were identified to address these risks and apply the lessons learned from flight 1 by the guidance, navigation, and control (GNC) team for the separation, engine test, and descent phases of flight.

- Development of an independent simulation for separation and an independent review of the HXRV simulation. These efforts were undertaken not only to identify errors in the simulations but also increase confidence that the simulations were valid.

- Detailed review of the HXRV and separation models and uncertainties. This review included assessment of the model fidelity and validation of the model with available data. 
- Performed additional analysis to evaluate the robustness of the flight controls and their associated risks. The additional analysis included robustness and sensitivity studies and stress case analysis.

The independent separation simulation and review of the HXRV simulation identified some differences or errors in the simulation, but these differences or errors did not have a significant impact on the predicted performance. The independent simulation and review did, however, considerably increase the confidence in the vehicle simulations. The navigation sensor model, actuator model, and system timing model were the HXRV models with the most significant updates and impact to the predicted performance of the vehicle. Analysis performed with the updated models predicted dramatically reduced stability margins for the entire mission. The maximum reduction in stability margin was on the order of 40 percent. Although the margins were significantly reduced, linear and nonlinear analysis during the engine test still predicted that the engine test requirements would be met. Stability margin predictions during the recovery maneuver and portions of the descent were found to no longer meet the $6 \mathrm{~dB}$ and $45 \mathrm{deg}(0.785 \mathrm{rad})$ nominal goals. The project accepted the reduced margins because they occurred during the secondary portion of the mission. In addition to the flight controls related models, the propulsion team identified updates to the engine performance database and uncertainties as a result of their risk assessment. The engine test angle of attack was also modified to increase the robustness of the engine performance. The change in the test angle of attack, in conjunction with the updates to the engine performance model, resulted in the cowl open, fuel on, and fuel off feedforward elements no longer being optimally tuned. Although the vehicle response during the engine transients was not optimal, the response was acceptable to the propulsion team. The additional stress testing that was performed for the engine test provided further confidence that the flight controls would be robust to disturbances, uncertainties, and unmodeled dynamics.

In addition to the HXRV system models, the separation analysis was also influenced by the updates in the separation aerodynamic model and uncertainties and piston models. The results of the separation analysis with the updated models showed that the flight controls continued to perform well. The additional stress cases and sensitivity analysis performed for separation indicated that the flight 1 version of the separation control logic was robust and that updates to the logic were not required.

\section{Mach 7 Flight 2 GNC Flight Test Results}

\section{A. Separation Event and Engine Test Performance}

The second flight of the HXRV took place on March 27, 2004. The HXLV delivered the HXRV close to the nominal target separation conditions. Table 1 shows the HXLV separation target conditions for each parameter, Mach 7 flight separation conditions, and deviations of the flight conditions from the target conditions. While the largest relative deviation was in flight path angle, this deviation was very close to the desired separation conditions. Based on the flight data, there was no evidence of re-contact of the HXRV with the HXLV during separation. Figure 9 shows a sequence of images of the separation event recorded by the right adapter camera. These images show the aft starboard side of the HXRV as the HXRV moved away from the adapter. Figure 10 shows a comparison of the flight angle of attack response with the preflight predictions. The initial separation transient was very close to the nominal simulation predictions. Following the initial separation transient, the HXRV took longer to reach the commanded angle of attack than had been predicted by preflight analysis. The slow transition to the engine test angle of attack is believed to be caused by an inaccurate preflight prediction of the trim pitching moment. The angle of attack to elevator feedforward schedule resulted in the vehicle trimming to a lower angle of attack during flight. The alpha controller design included no proportional error feedback at low angles of attack; therefore, the trim error in the trim bias was removed entirely by the integrator. Preflight analysis did not predict this behavior because uncertainty in the trim pitching moment was not captured in the aerodynamic database uncertainty model. Figure 11 shows the observed wing deflection through the separation event. Prior to the cowl door opening, the wing deflections were offset from the nominal predictions and were notably outside the Monte Carlo predictions. Although the HXRV took longer to reach the desired engine test conditions, the HXRV did achieve the conditions just prior to the engine cowl door opening. The pistons that push the HXRV from the HXLV fired simultaneously

and generated very little lateral-directional transient. Figure 12 shows the sideslip angle response during the separation event. 
Table 1. HXLV flight 2 separation conditions and comparison to target conditions.

\begin{tabular}{cccc}
\hline \hline Parameter & Target & Flight 2 values & Deviation \\
\hline Time to condition & $\leq 100.0 \mathrm{~s}$ & $93.44 \mathrm{~s}$ & $0.0 \mathrm{~s}$ \\
Altitude & $93,932 \mathrm{ft}$ & $94,069 \mathrm{ft}$ & $137 \mathrm{ft}$ \\
Mach $^{*}$ & 7.075 & 6.946 & -0.129 \\
Dynamic pressure $^{*}$ & $1,066 \mathrm{psf}$ & $1024 \mathrm{psf}$ & $-42.0 \mathrm{psf}$ \\
Flight path elevation angle $_{\text {Booster angle of attack }}^{2.0 \mathrm{deg}}$ & $2.4 \mathrm{deg}$ & $+0.4 \mathrm{deg}$ \\
Booster sideslip angle & $0.0 \mathrm{deg}$ & $0.08 \mathrm{deg}$ & $+0.08 \mathrm{deg}$ \\
\hline \hline
\end{tabular}

${ }^{*}$ Computed using best estimate atmospheric model.
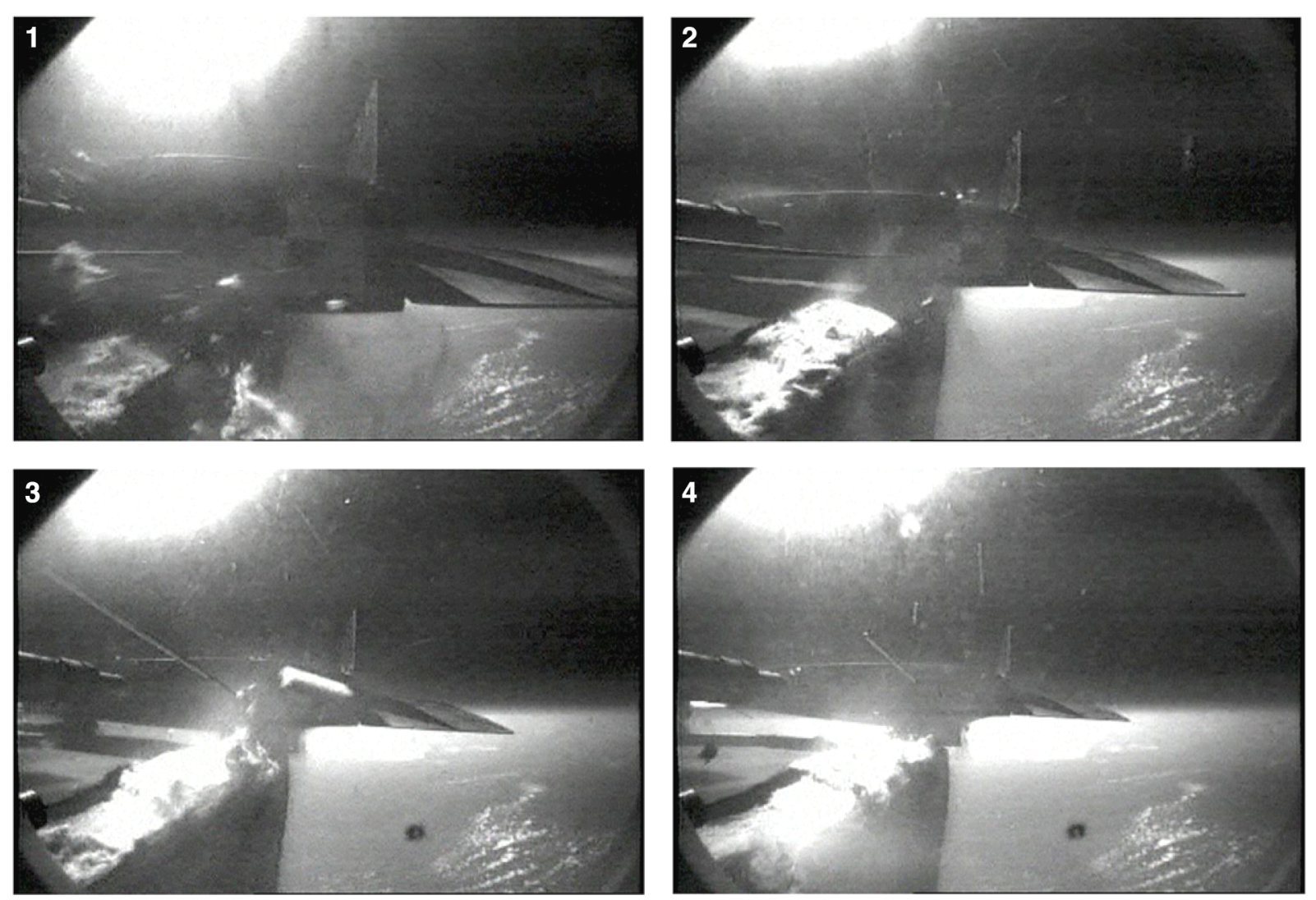

Figure 9. Separation event images from right adapter camera. 


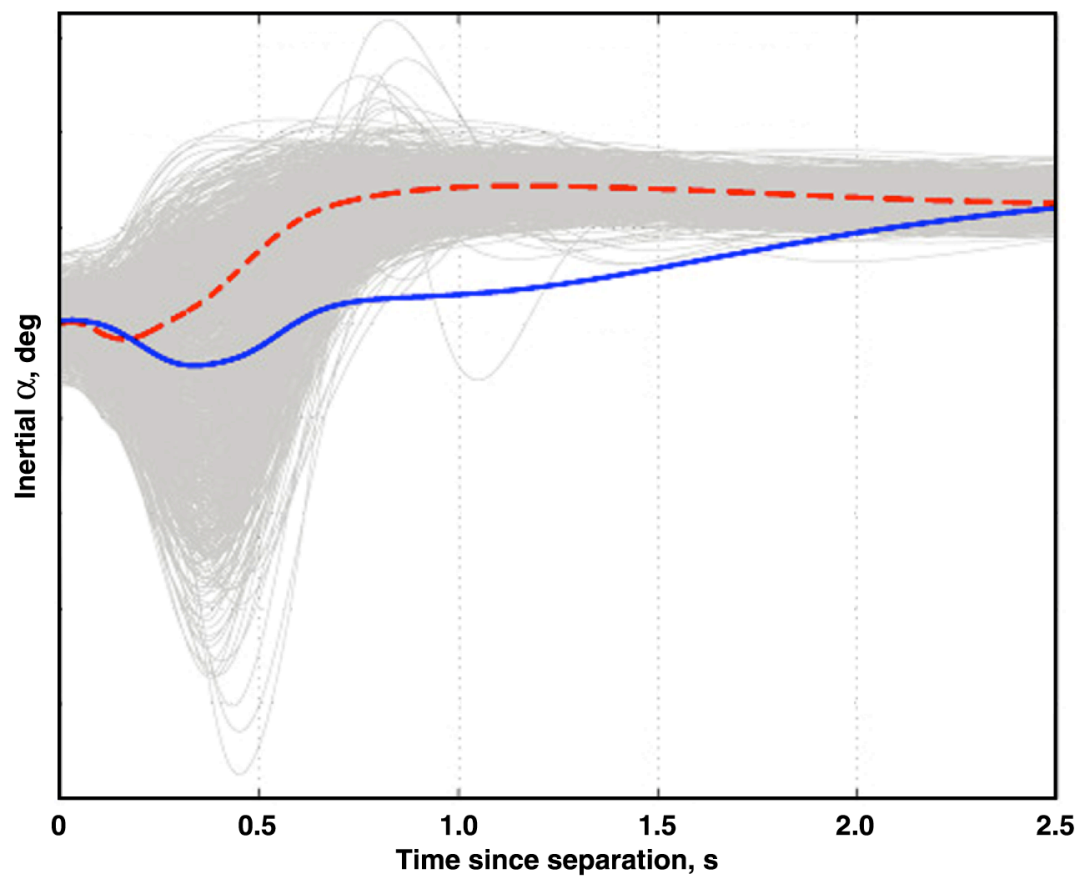

Flight data

- - Simulation

Monte Carlo data

Figure 10. Comparison of flight inertial angle of attack and preflight predictions during separation event.
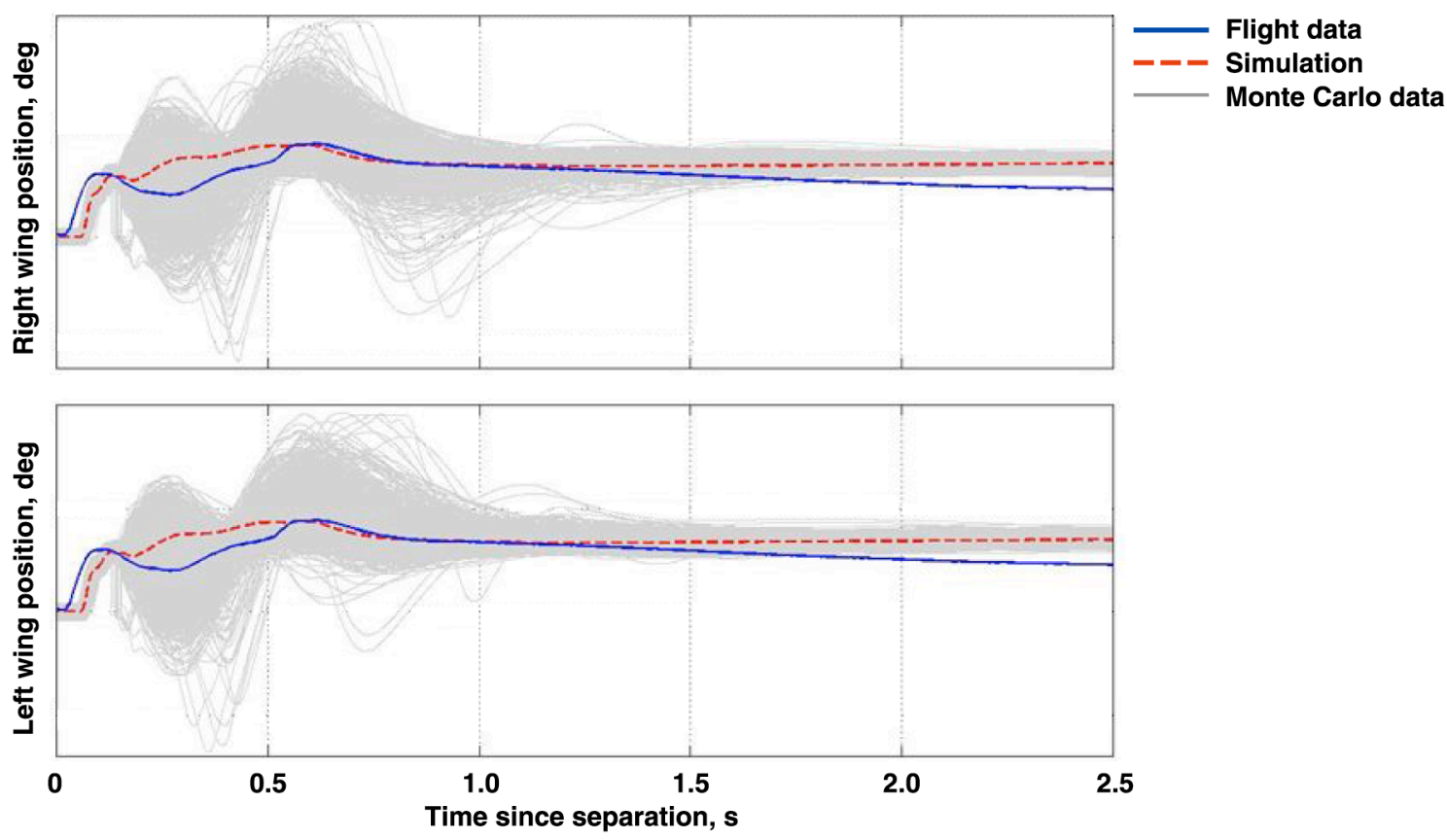

Figure 11. Comparison of flight wing positions and preflight predictions during separation event. 


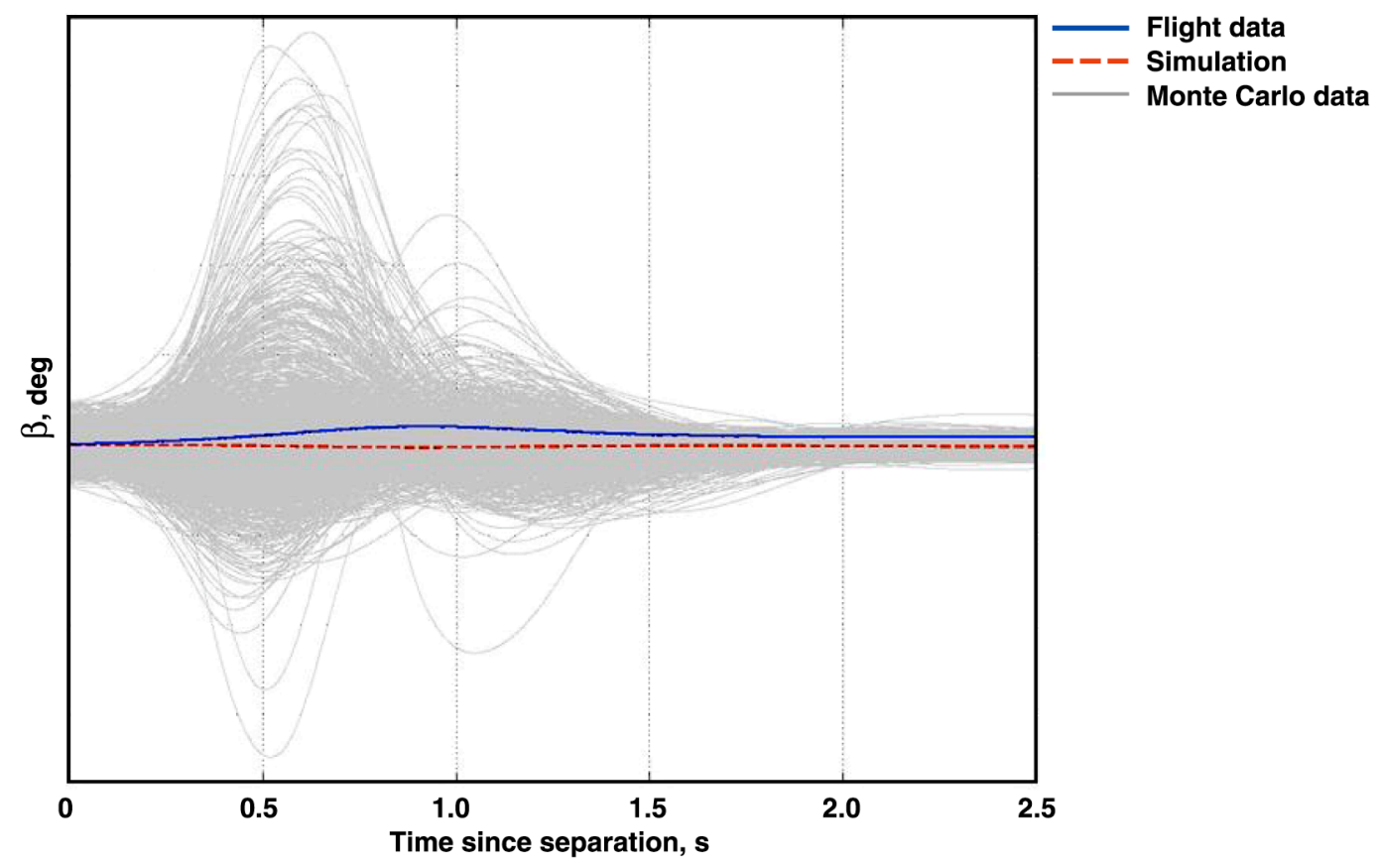

Figure 12. Comparison of flight inertial sideslip angle and preflight predictions during separation event.

The nominal and Monte Carlo preflight analysis predicted a nosedown transient when the cowl door opened as shown in Figs. 13 and 14. The cowl open transient seen during the flight was noseup and outside all predictions. This transient is likely caused by a misprediction of the dynamics caused by the cowl door opening. During the engine test, the HXRV maintained the engine test conditions well within the requirements. The inertial angle of attack response during the engine test is compared with the preflight Monte Carlo in Fig. 13. The inertial angle of attack fell outside the Monte Carlo bounds during the period from 11-13 s. As Fig. 13 shows, the angle of attack response during the fuel off transient was close to the lower bounds on the Monte Carlo predictions. These excursions from preflight predictions are probably the result of differences between the predicted engine database and in-flight engine performance. Although there was a steady state offset in inertial sideslip throughout the engine test, the inertial sideslip angle was within the performance requirements (Fig. 15). The bank angle was near zero during the engine test with the exception of the cowl open PID maneuver. Figures 14 and 15 show the angle of attack and sideslip responses during the cowl open PID maneuver. The HXRV remained under control and the response was very close to the nominal predictions. The inaccurate prediction of the trim pitching moment identified during separation caused the wing trim positions offset from the engine test through part of the descent as shown in Fig. 16. 

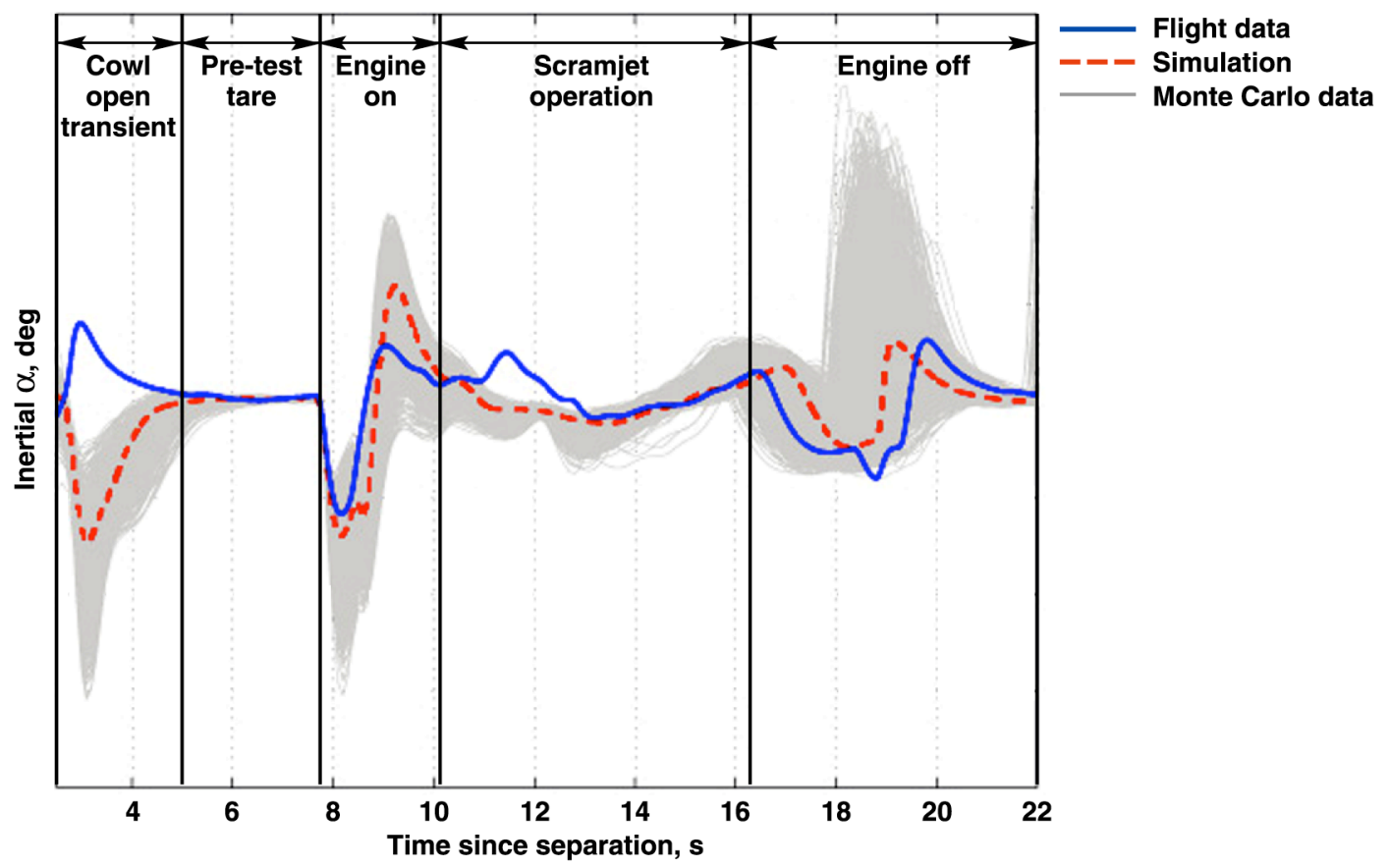

Figure 13. Comparison of flight inertial angle of attack and preflight predictions during engine test.

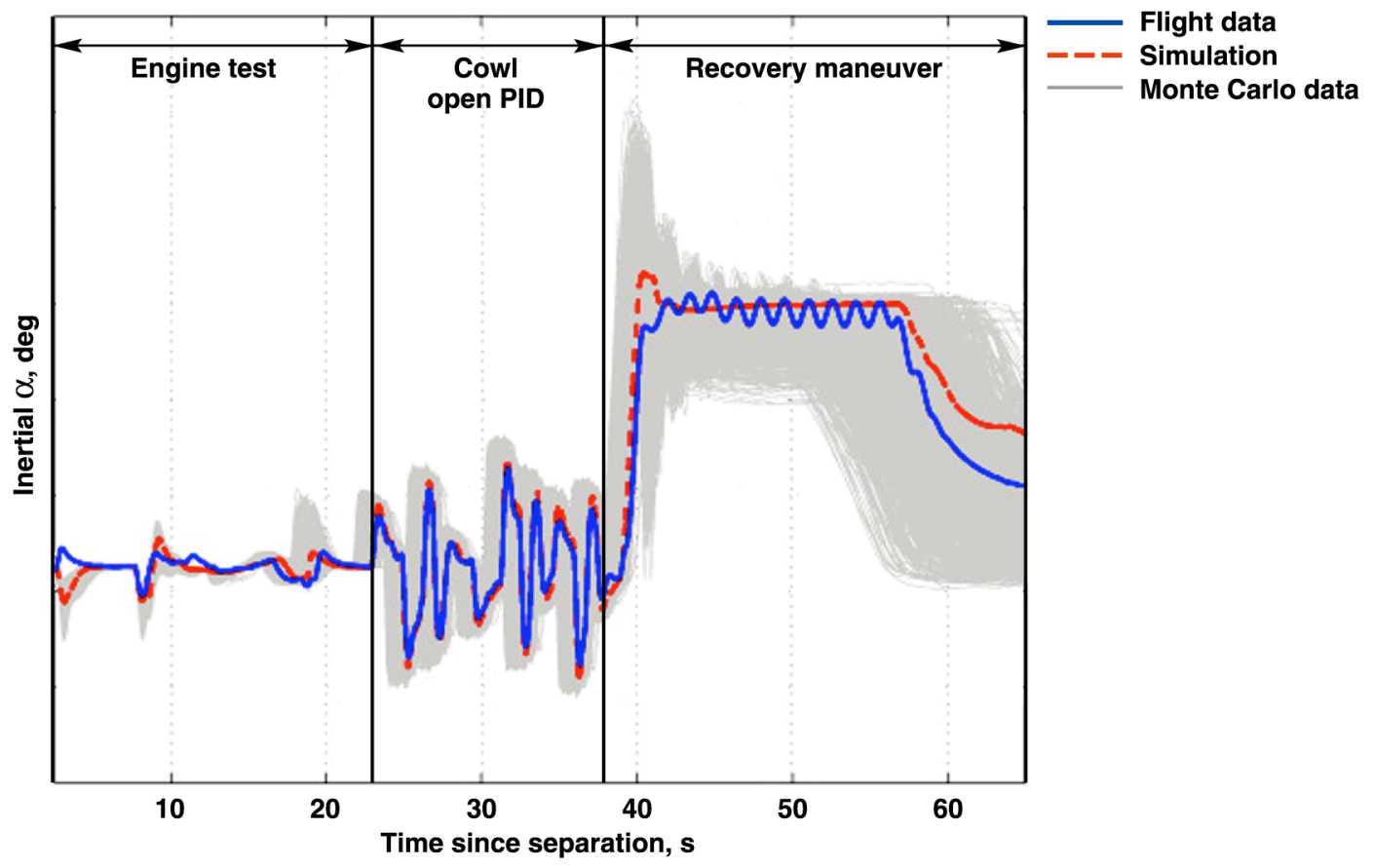

Figure 14. Comparison of flight inertial angle of attack and preflight predictions from engine test through recovery maneuver. 


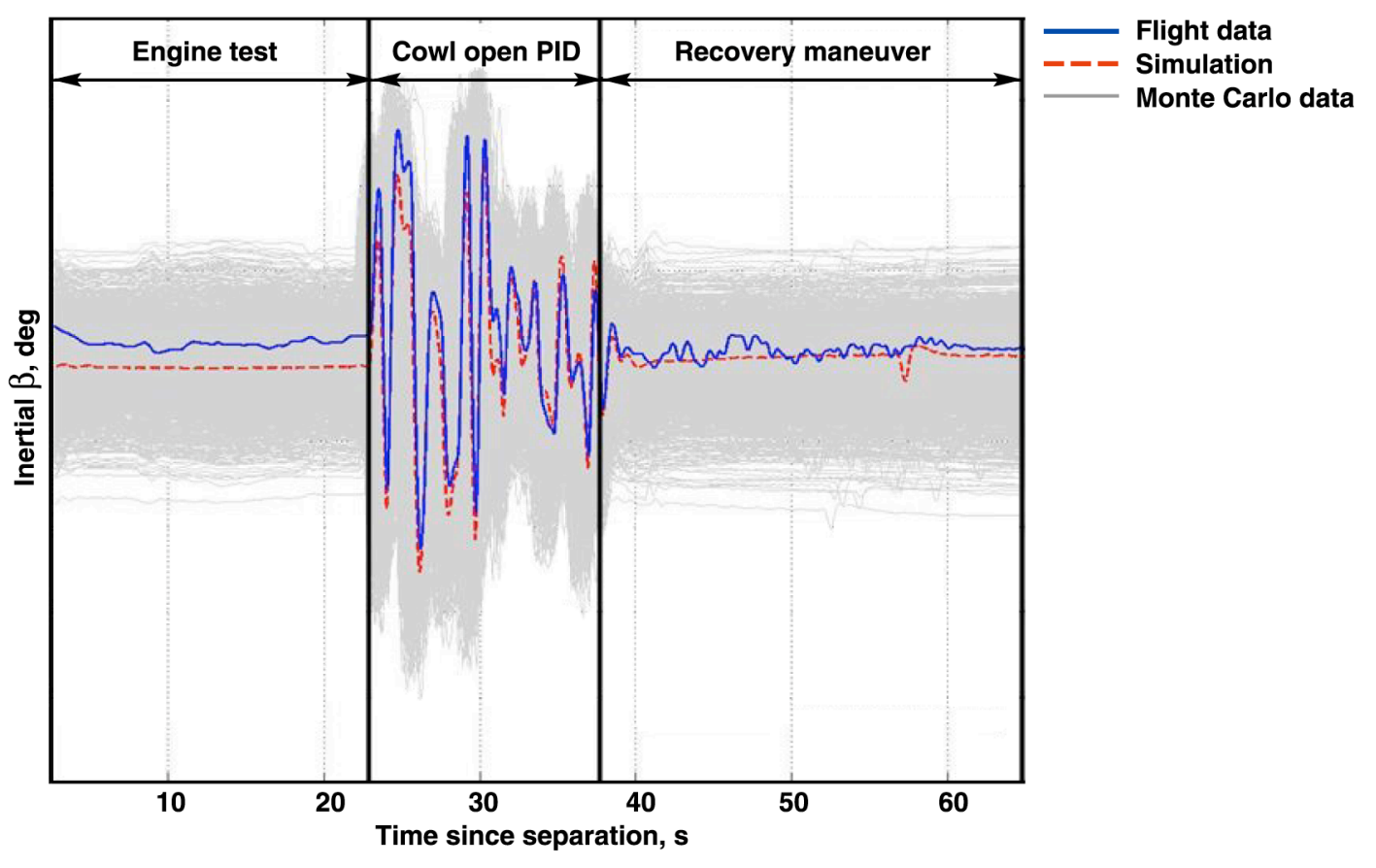

Figure 15. Comparison of flight inertial sideslip angle and preflight predictions from engine test through recovery maneuver.

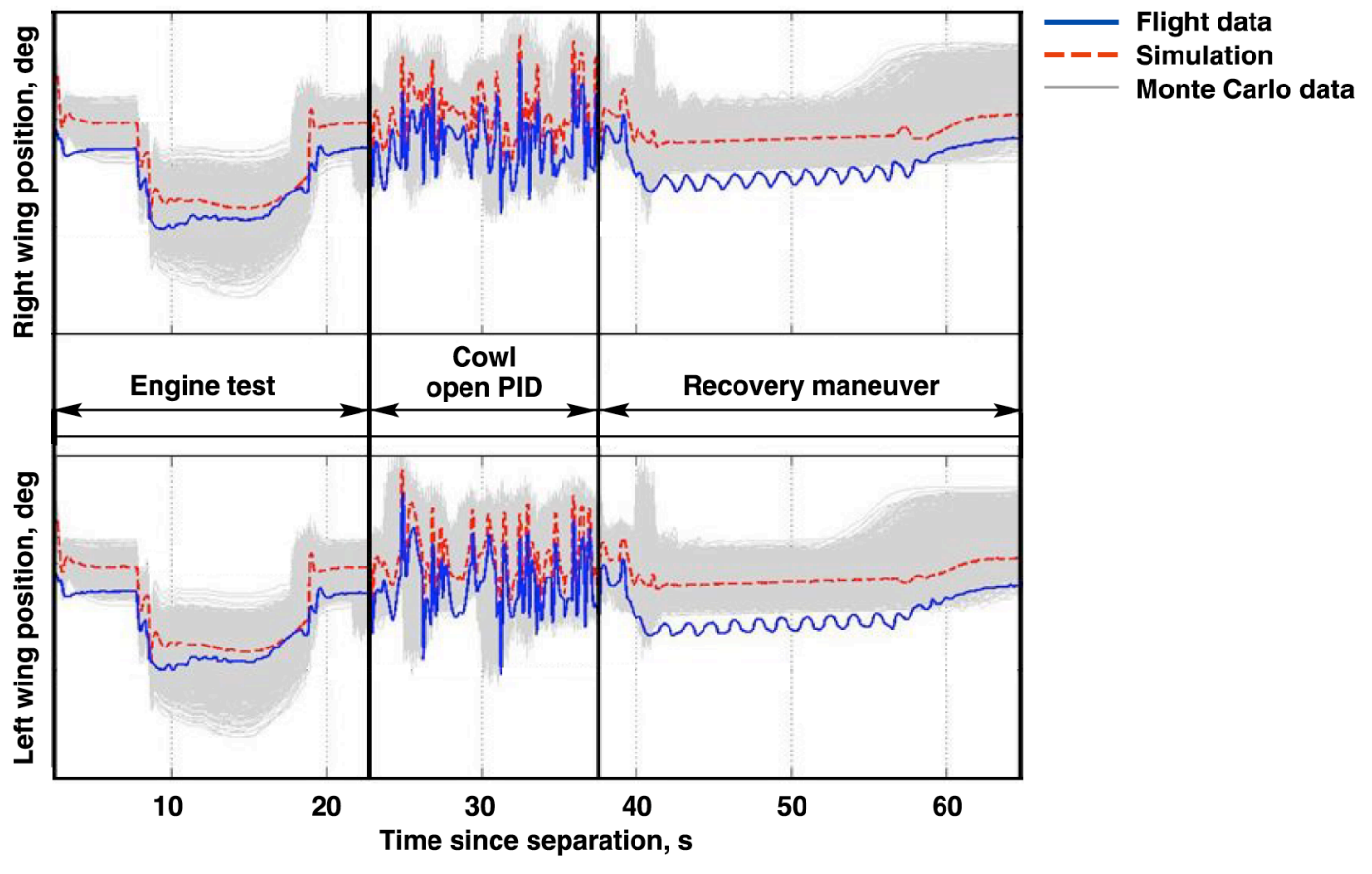

Figure 16. Comparison of flight all moving wing positions and preflight predictions from engine test through recovery maneuver. 


\section{B. Descent Performance}

After the engine cowl door closed, the HXRV increased the angle of attack to arrest the buildup in dynamic pressure and heating. During the recovery maneuver, the HXRV experienced angle of attack small amplitude oscillations at a frequency of approximately $0.65 \mathrm{~Hz}$ as shown in Fig. 14. The preflight predictions did not include any cases with sustained oscillations during the recovery maneuver. Large spikes in the wing spindle torque readings and actuator currents occurred during the angle of attack oscillations. The cause of the oscillations, abnormal spindle torques, and anomalous actuator currents is still under investigation. The investigation of this anomaly includes a review of the longitudinal aerodynamic parameters, wing spindle friction, wing hinge moments, and shock locations relative to the wing.

After the recovery maneuver, the vehicle transitioned to the descent mode. The vehicle maintained control and performed well during the descent. All descent PID maneuvers were performed successfully. Figure 17 shows a plot of the vehicle altitude and the reference trajectory. The vehicle altitude tracked the reference profile until the trajectory transitioned to the second polynomial at approximately $350 \mathrm{~s}$. The HXRV was unable to follow the second descent polynomial and the altitude fell below the reference trajectory because of the limits on the onboard-estimated dynamic pressure and angle of attack. The inability of the HXRV to follow the reference trajectory is the result of the reference trajectory being developed early in the program and not kept up-to-date with vehicle models. Figure 18 shows that the flight trajectory was close to the nominal simulation results and was well within the Monte Carlo predictions. Dynamic pressure was lower than the nominal predictions throughout most of the descent as shown in Fig. 19. The dynamic pressure was at the lower limit late in the descent. Figure 20 shows the inertial angle of attack response during the descent phase. The four descent research maneuver sets, which included PID maneuvers, frequency sweeps, and POPU maneuvers, can clearly be seen in the angle of attack response. Near the end of the flight, the angle of attack reached the upper limit. This resulted in the angle of attack response during the fourth POPU being clipped and the controller failing to track the normal acceleration command. This was similar to the performance seen in the nominal simulation. Figure 21 shows the comparison of the in-flight bank angle to the predictions. When initiated, descent guidance commanded a bank angle to acquire the reference trajectory. During the Mach 7 flight, guidance commanded a bank that was less than the nominal predictions. The bank angle was within Monte Carlo predictions throughout the descent except for the deviation late in the descent. At that point, the HXRV banked $30 \mathrm{deg}(0.523 \mathrm{rad})$ left wing down. The vehicle control system rejected this disturbance. The cause of this upset has not been conclusively determined, but the upset might have been caused by winds or unmodeled aerodynamics. Preflight predictions indicated reduced stability and robustness transonically at higher angles of attack. At approximately $492 \mathrm{~s}$ after separation, the HXRV transitioned to the "approach mode." During the "approach mode," the rate of descent was decreased from a peak of $715 \mathrm{ft} / \mathrm{s}(218 \mathrm{~m} / \mathrm{s})$ to $440 \mathrm{ft} / \mathrm{s}(134 \mathrm{~m} / \mathrm{s})$ prior to impact. The HXRV impacted the ocean at approximately $400 \mathrm{nmi}(741 \mathrm{~km})$ downrange from the drop point at Mach 0.92. Table 2 contains the last recorded flight condition, which indicated that the vehicle was controlled to the water. The impact location was well within the preflight prediction as shown in Fig. 22. The vehicle fell short of the aim point as a consequence of not being able to follow the reference altitude profile. 


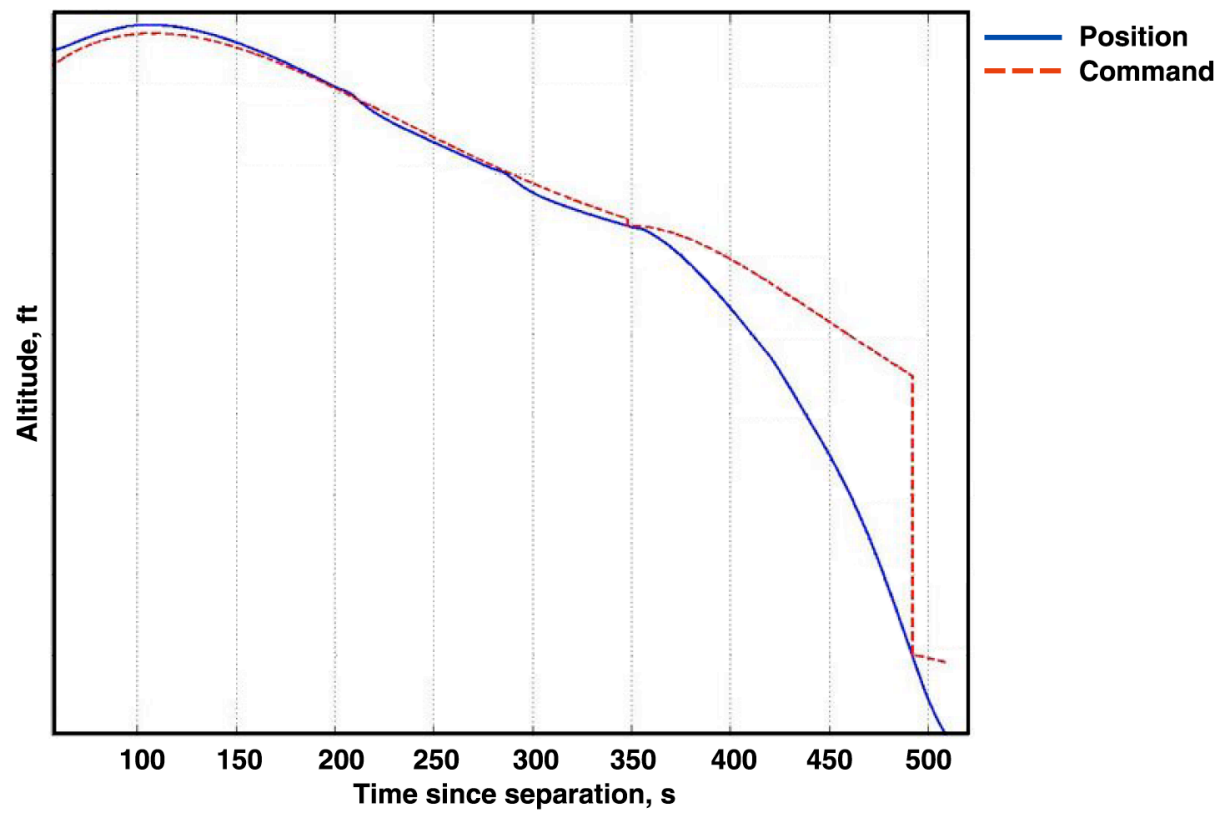

Figure 17. Comparison of flight altitude position and command during descent.

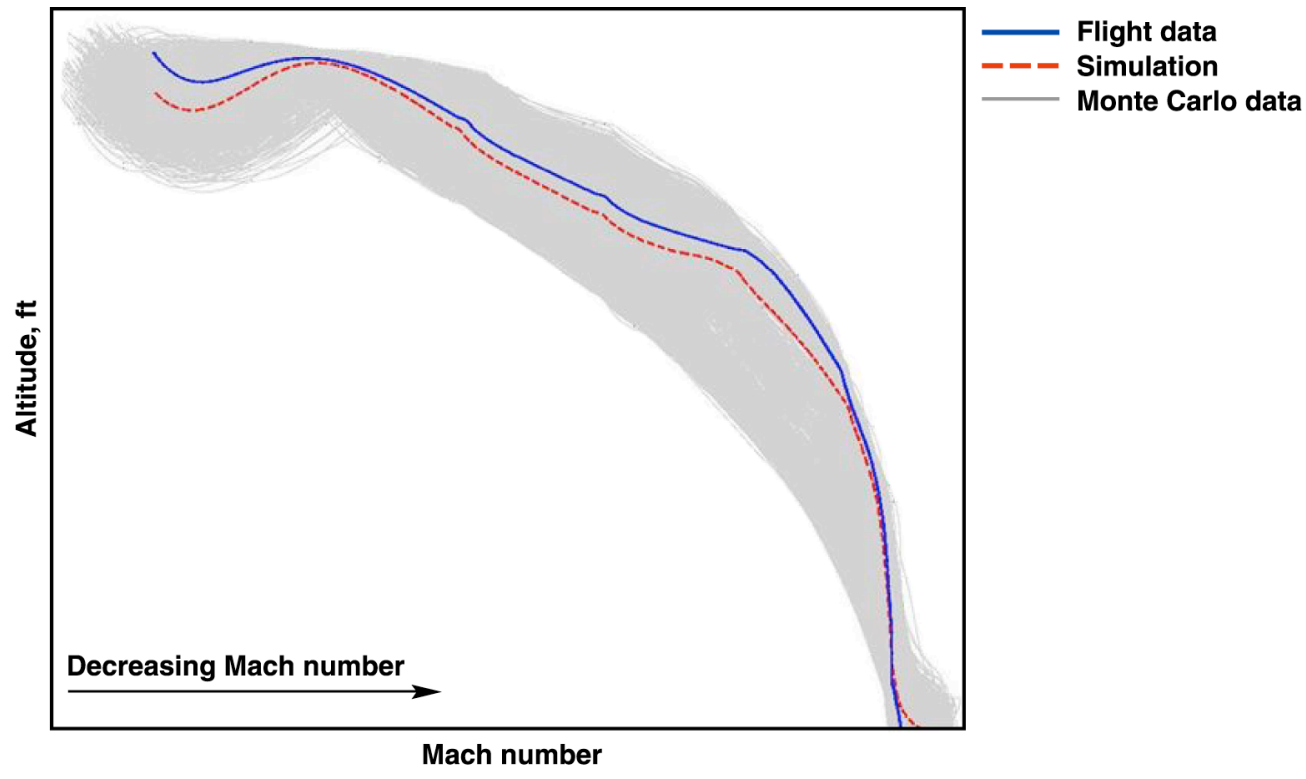

Figure 18. Comparison of flight altitude and preflight predictions during descent. 


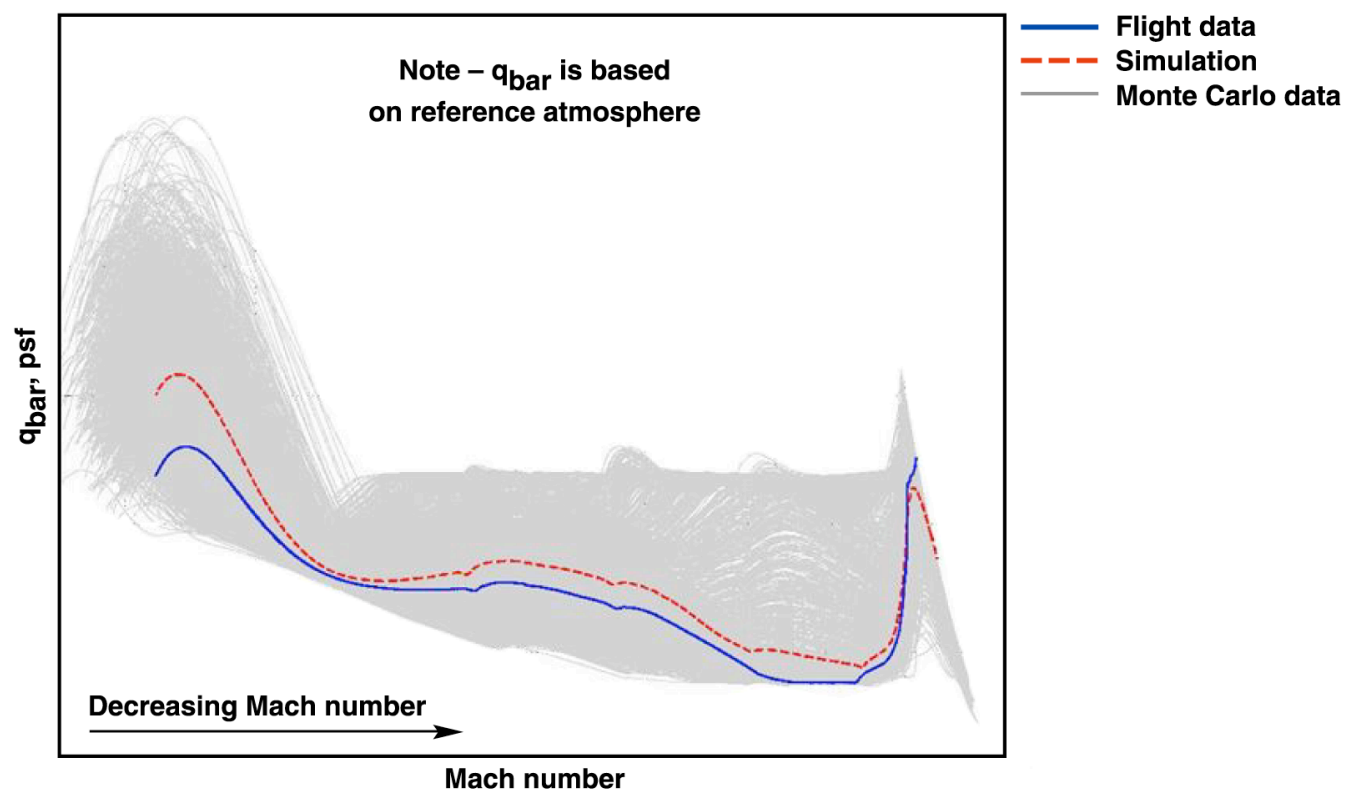

Figure 19. Comparison of flight dynamic pressure and preflight predictions during descent.

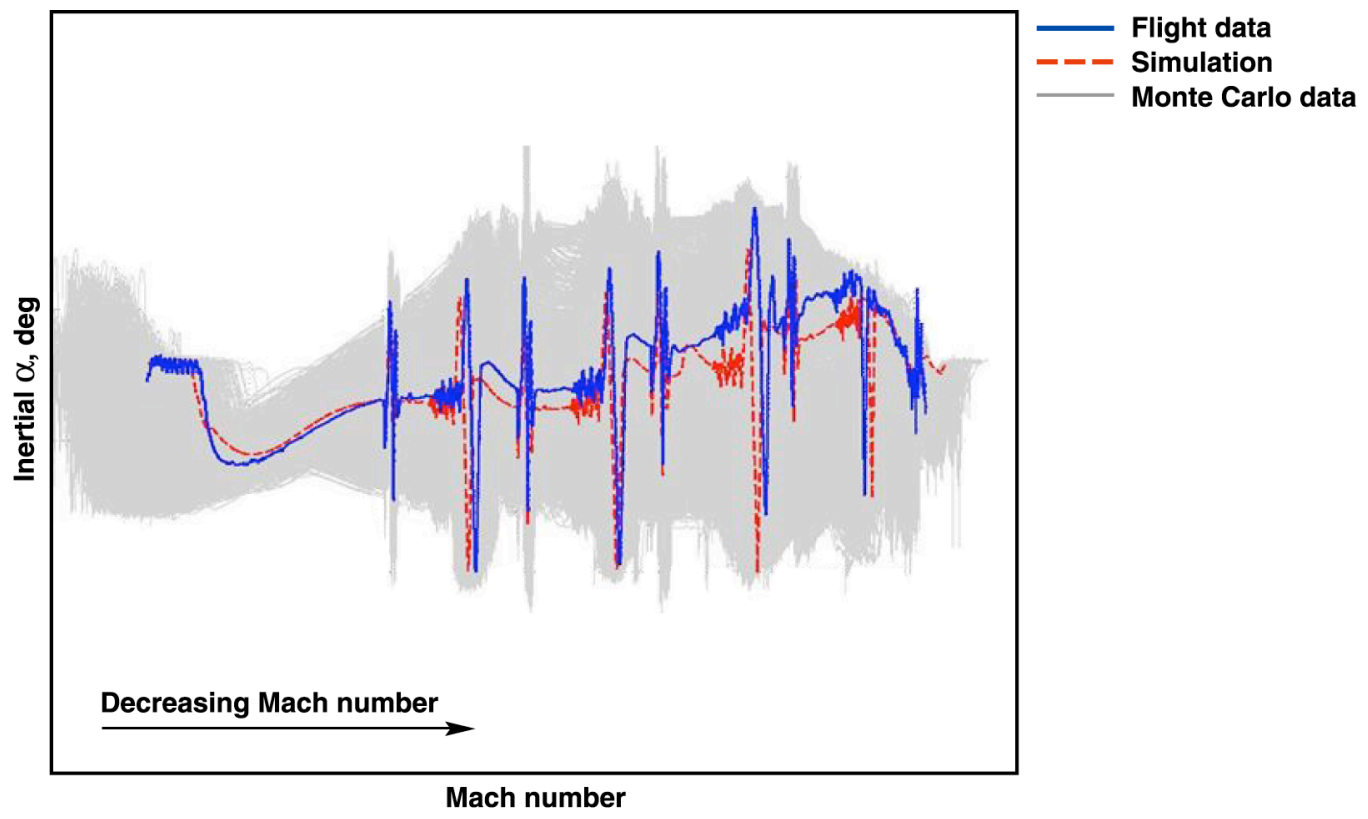

Figure 20. Comparison of flight inertial angle of attack and preflight predictions during descent. 


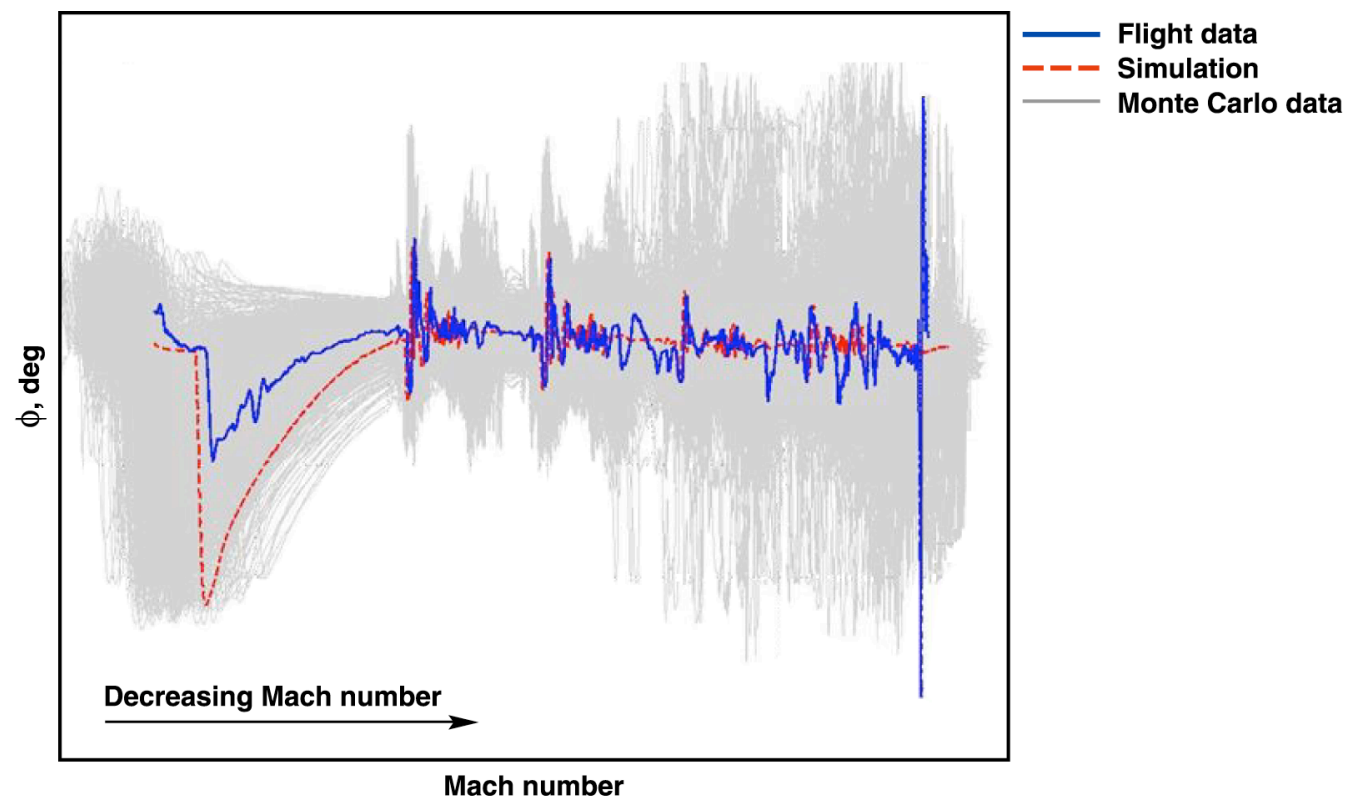

Figure 21. Comparison of flight bank angle and preflight predictions during descent.

Table 2. 'Landing' conditions.

\begin{tabular}{cccccc}
\hline \hline $\begin{array}{c}\text { Altitude, } \\
\mathrm{ft}\end{array}$ & $\begin{array}{c}\text { Mach no., } \\
(-)\end{array}$ & $\begin{array}{c}\text { Altitude rate, } \\
\mathrm{ft} / \mathrm{s}\end{array}$ & $\begin{array}{c}\text { Alpha, } \\
\mathrm{deg}\end{array}$ & $\begin{array}{c}\text { Flight path angle, } \\
\mathrm{deg}\end{array}$ & $\begin{array}{c}\text { Bank angle, } \\
\mathrm{deg}\end{array}$ \\
\hline 41.86 & 0.92 & -440.53 & 6.03 & -25.67 & 1.29 \\
\hline \hline
\end{tabular}

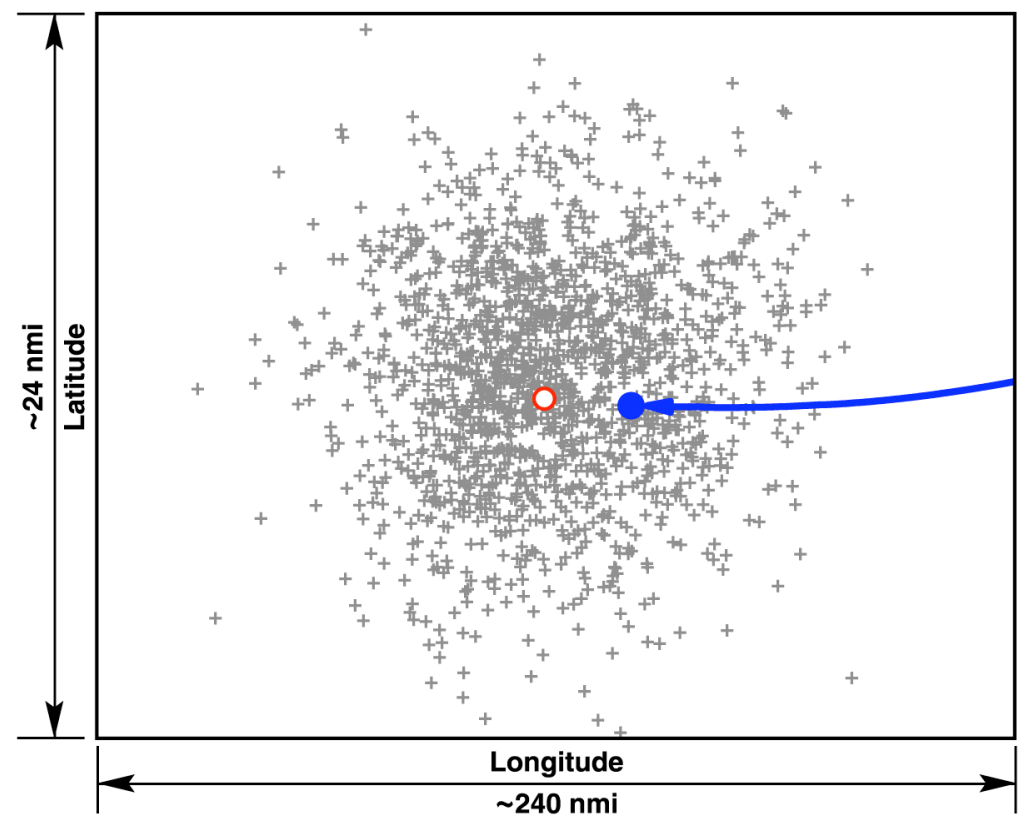

Aim point

- Splash point

+ Monte Carlo splash point

Flight path

Figure 22. Research vehicle splash point comparison with preflight Monte Carlo predictions. 


\section{GNC Research Objectives}

The intent of the HXRV FADS system research is to collect pressure data and evaluate the FADS algorithms ${ }^{6}$ which are used to estimate angle of attack and dynamic pressure. During the descent, the inertial angle of attack is augmented with the FADS-estimated angle of attack to generate the estimated angle of attack as a means of developing confidence in the FADS algorithms for applications of this type. The dynamic pressure estimation is performed onboard the HXRV but is not used onboard because of the lack of maturity of the algorithm. The detailed evaluation of the angle of attack and dynamic pressure algorithms is performed postflight using the pressure data. A discussion of the results of the onboard estimation of the angle of attack and dynamic pressure follows. The detailed analysis and assessment of the FADS estimation algorithms is in progress.

The angle of attack and dynamic pressure FADS algorithms performed adequately; however, there were areas for improvement. Figure 23 shows a comparison of the onboard FADS estimate for angle of attack and the inertial angle of attack. The FADS-estimated angle of attack was very close to the inertial solution. The maximum difference between the estimated and inertial angles of attack was less than $1 \mathrm{deg}(0.0174 \mathrm{rad})$. The FADS-estimated angle of attack was declared invalid at approximately $350 \mathrm{~s}$ after separation. This resulted in the FADS-estimated angle of attack being set to the inertial angle of attack. The FADS estimate of the dynamic pressure compared with the onboard inertial solution matched the dynamics but has a constant offset on the order of $100 \mathrm{psf}(4.79 \mathrm{kPa})$ as shown in Fig. 24. Until the detailed analysis and assessment has been completed, the HXRV FADS system should be considered preliminary and a developmental system.

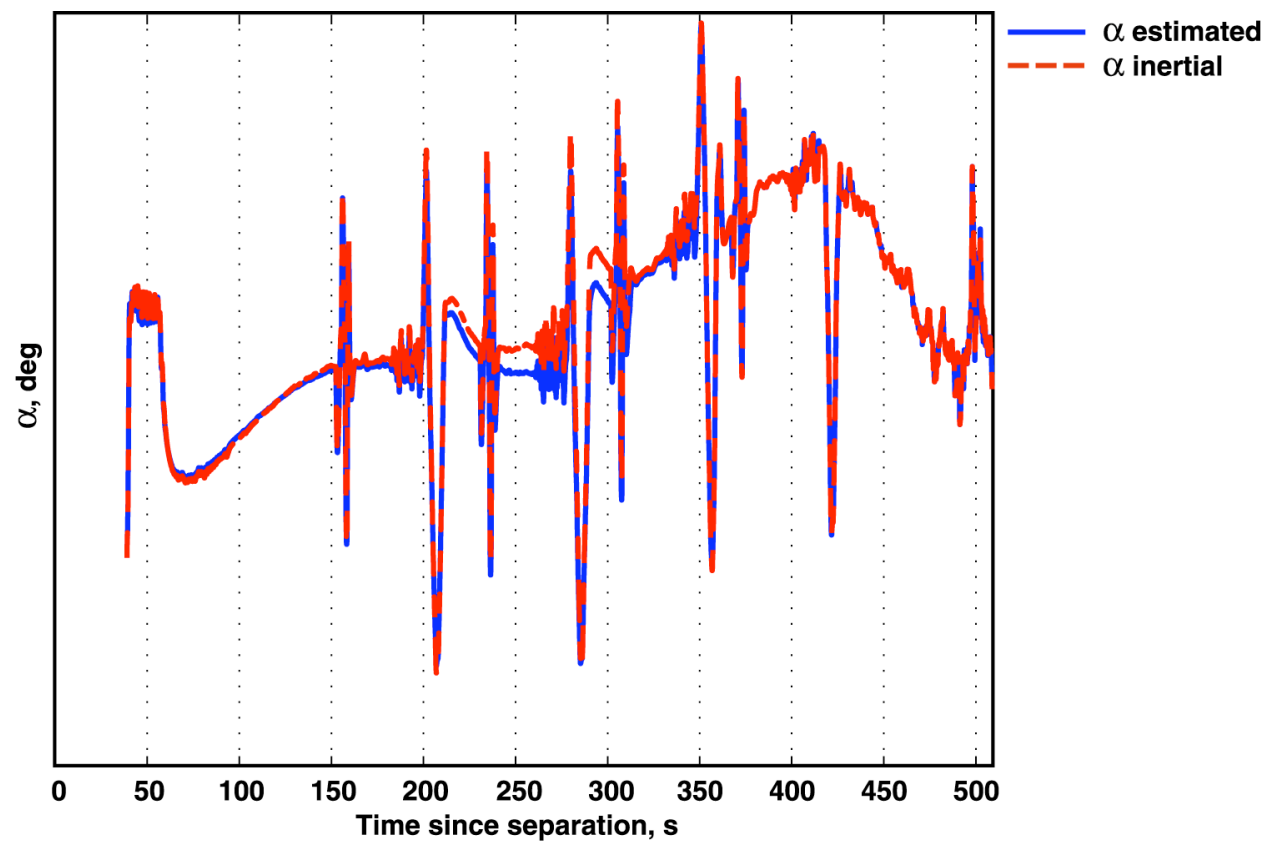

Figure 23. Comparison of FADS estimated and inertial angle of attack. 


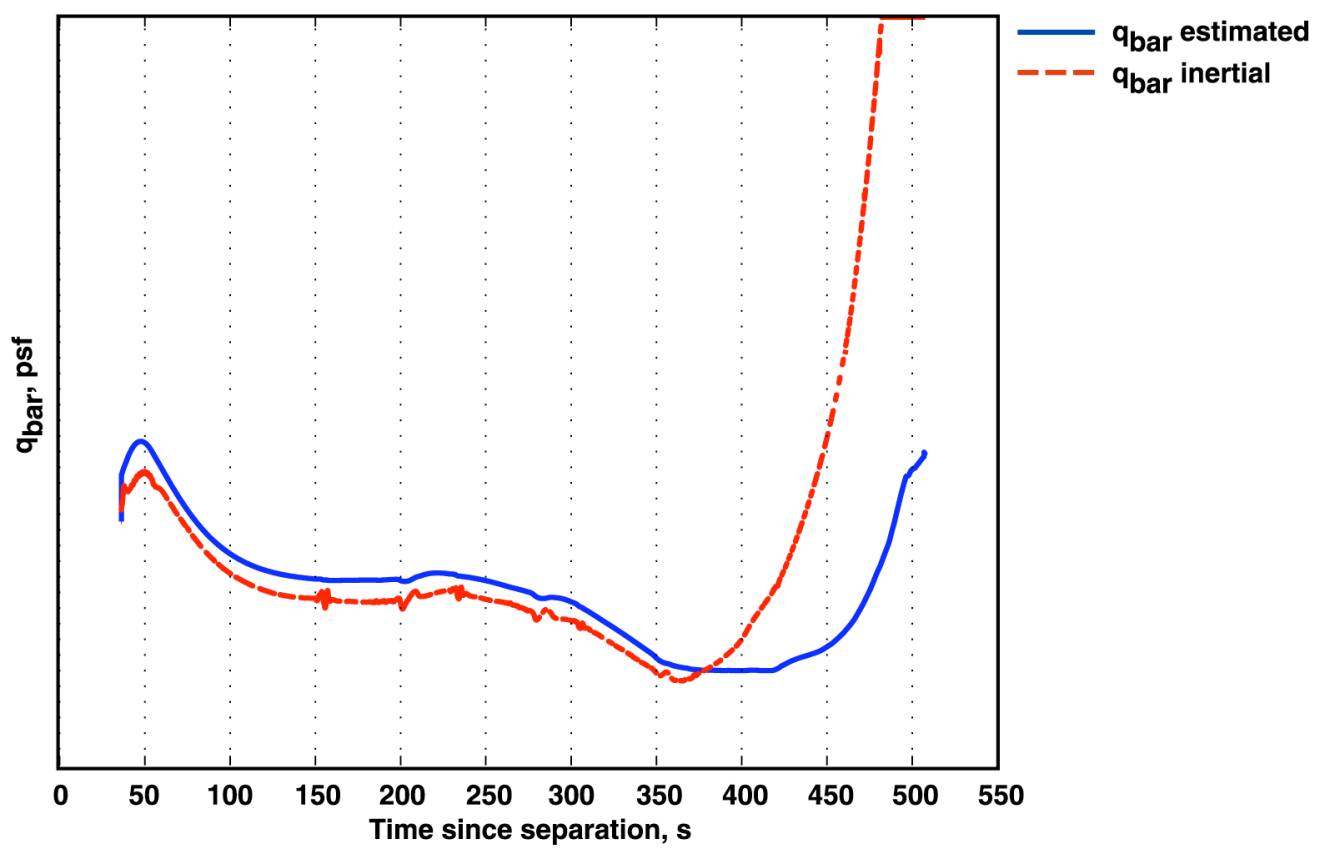

Figure 24. Comparison of FADS estimated and inertial dynamic pressure.

The flight controls research, flight frequency response estimation, was performed utilizing a technique to identify the vehicle frequency response at specific flight conditions in the descent flight envelope. During the descent phase, a set of input signals, Schroeder sweeps, were simultaneously applied to the elevator, aileron, and rudder command paths. The input signals were tailored to excite each of the three paths at different frequencies making it possible to extract closed-loop frequency responses for each axis at the same time. Figure 25 shows an example of the elevator, aileron, and rudder commands for the second maneuver. Because this technique excited all of the control loops at the same time, the technique allowed for shorter overall excitation times required to accurately identify the frequency response characteristics compared with traditional methods such as standard frequency sweeps. The short excitation time was particularly important to the HXRV because the HXRV had very limited ability to maintain a given flight condition during the descent, which is necessary for accurate results. In addition to the frequency responses, singular values for the multiple-input/multiple-output system could be assessed. This technique for extracting closed-loop frequency responses had proven successful in simulation studies conducted for other projects, such as the $\mathrm{X}-31 .^{7}$ 

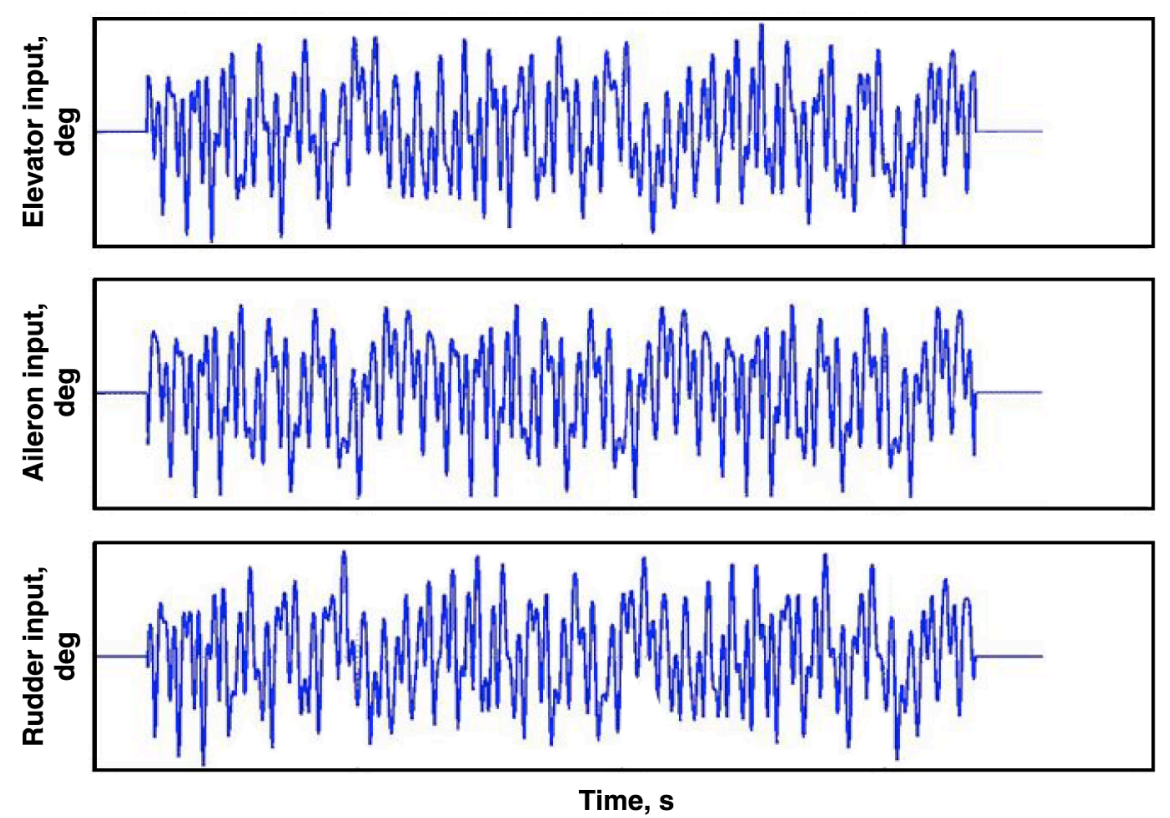

Figure 25. Surface commands for second frequency sweep.

Frequency responses were extracted from the test input and vehicle response using Fast Fourier Transform (FFT) and Chirp- $Z$ techniques. Chirp- $Z$ techniques extract the response only at the frequencies contained in the input signal while the FFT techniques calculate the frequency response over a wider range of frequencies. The frequency responses generated from flight data using both FFT and Chirp-Z methods match the linear analysis predictions at the same flight conditions for the elevator and aileron loops. Figures 26 and 27 show examples of the comparisons for the second frequency sweep for the elevator and aileron, respectively. The linear frequency responses were obtained at the start, end, and mean flight conditions seen during the flight controls frequency sweeps. Stability margins and crossover frequencies for the elevator and aileron loops match the linear predictions very well. The rudder loop responses were determined to be invalid. The inaccurate rudder responses are believed to be a result of the coupling between the aileron and rudder loops and inadequate frequency spacing between the aileron and rudder input signals. Simulation analysis performed before flight indicated that there would be excessive correlation between the aileron and rudder loop responses, which would preclude obtaining accurate data for the rudder loop response. Updates to the HXRV flight code were required to fix or remove the rudder frequency sweeps. The project decided to accept this deficiency because the deficiency was identified very close to the flight date, affected only a secondary mission objective, and would cause a significant impact to the flight schedule. The poor quality of the rudder loop frequency responses precluded any type of multiple-input/multiple-output stability analysis. 

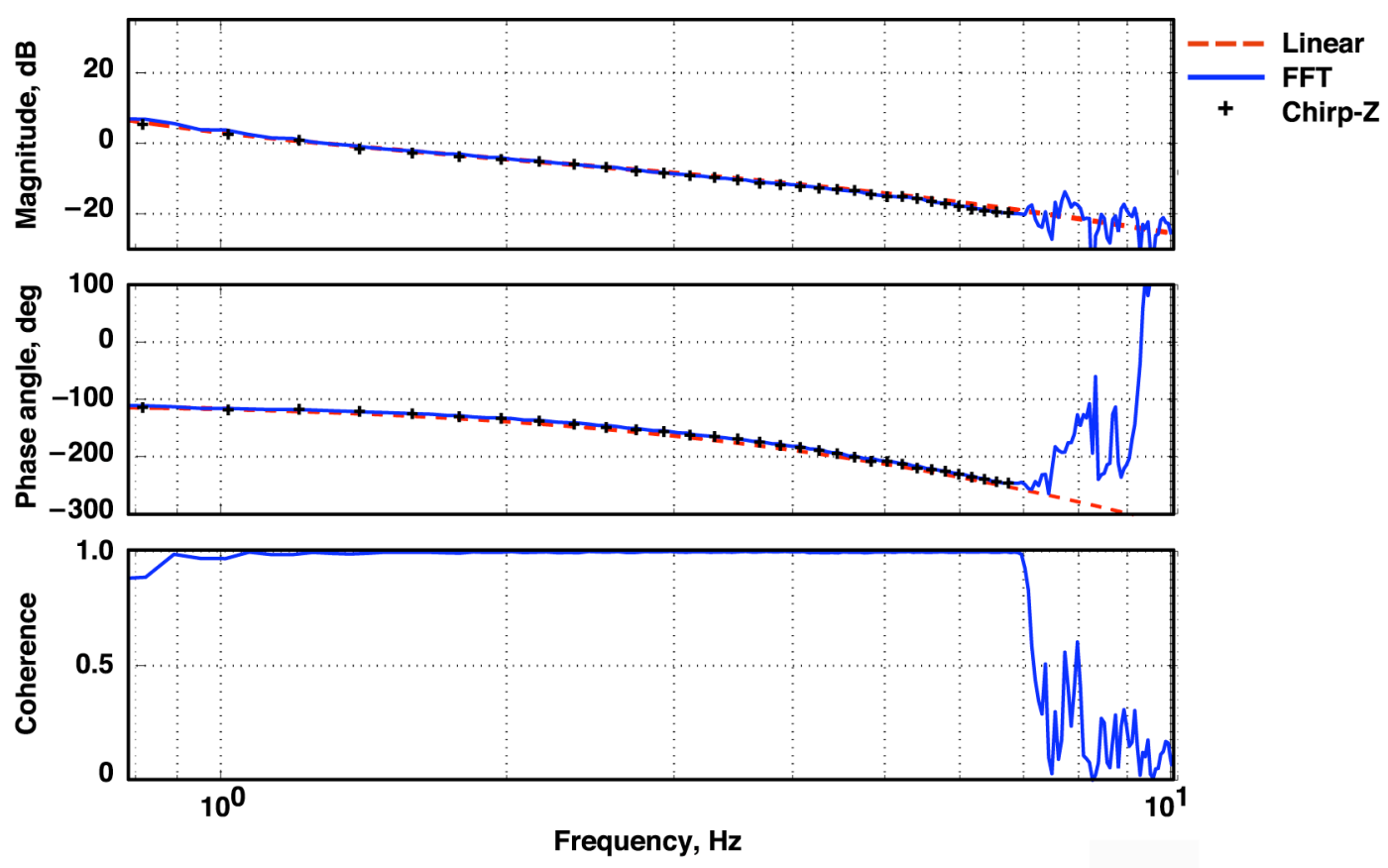

Figure 26. Comparison of elevator frequency responses for second descent maneuver.

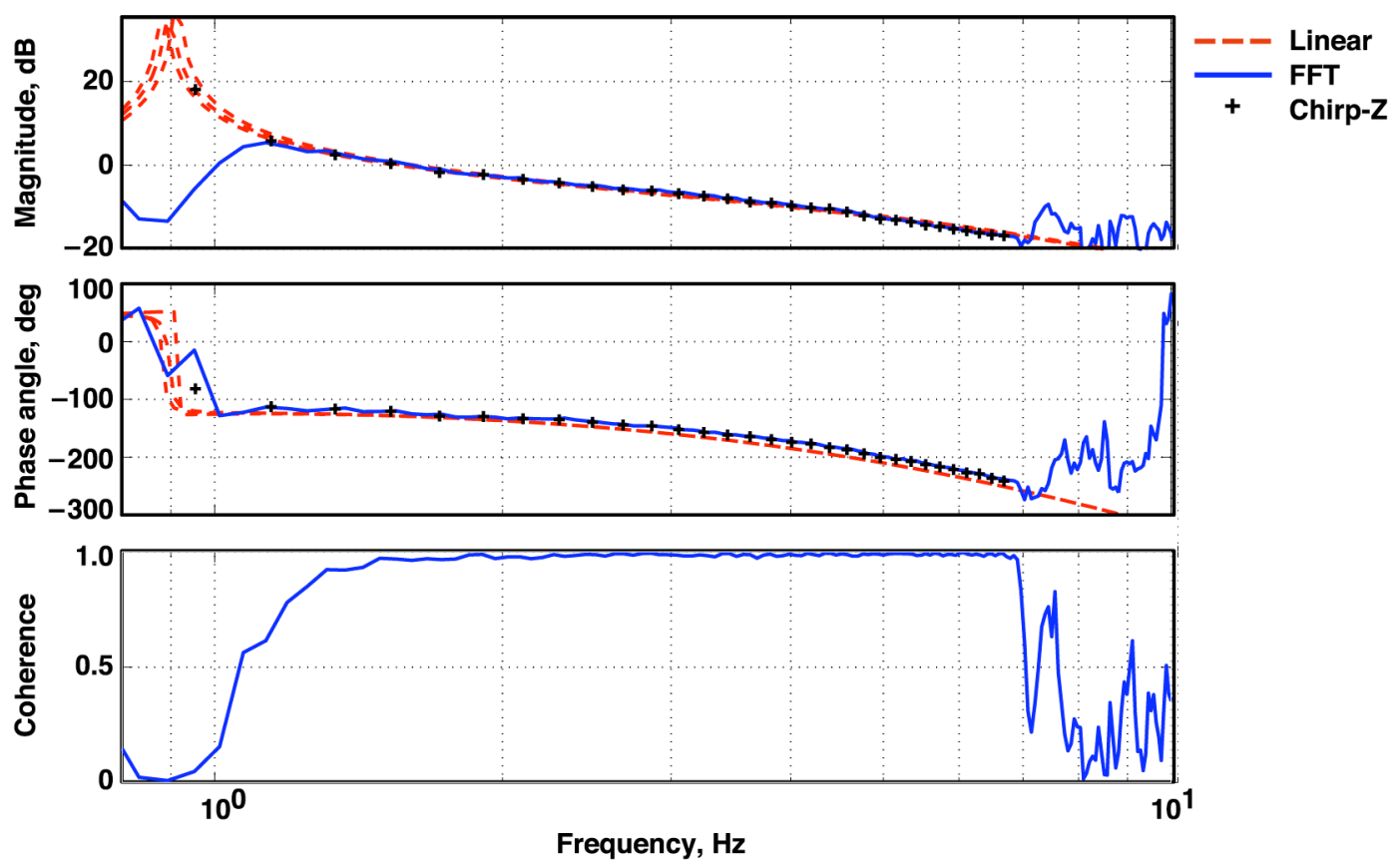

Figure 27. Comparison of aileron frequency responses for second descent maneuver. 


\section{Conclusion}

An overview of the Mach 7 separation control logic, guidance, and flight control system was presented. The flight 2 research vehicle performance during the separation event, engine test, and descent phases was discussed. The separation of the HXRV from the HXLV was close to nominal; and although the HXRV took longer to reach the desired conditions, the engine test conditions were met prior to the cowl door opening. The HXRV rejected the cowl open transient that was outside the preflight predictions and maintained the engine test conditions well within the requirements. During the recovery maneuver, small amplitude angle of attack oscillations occurred that are still under investigation. After the recovery maneuver, the vehicle transitioned to the descent mode, maintained control, and performed close to the nominal predictions through the descent. The impact location was well within the preflight prediction. An overview of the additional flight controls HXRV research objectives and results were presented. Initial comparisons between the FADS and inertial angles of attack showed good agreement. The frequency responses generated from the in-flight flight controls frequency sweeps matched the linear predictions at the same flight conditions very well. Overall, flight 2 of the Hyper-X research vehicle was very successful, achieving both the primary mission objectives and the additional research objectives.

\section{References}

${ }^{1}$ McClinton, C. R., Rausch, D. R., Sitz, J., and Reukauf, P., "Hyper-X Program Status," AIAA/NAL-NASDA-ISAS 10th International Space Planes and Hypersonic Systems and Technologies Conference, Kyoto, Japan, AIAA 2001-1910, April 24-27, 2001.

${ }^{2}$ Huebner, L. D., Rock, K. E., Ruf, E. G., Witte, D. W., and Andrews, E. H. "Hyper-X Flight Engine Ground Testing for X-43 Flight Risk Reduction," AIAA/NAL-NASDA-ISAS 10th International Space Planes and Hypersonic Systems and Technologies Conference, Kyoto, Japan, AIAA 2001-1809, April 24-27, 2001.

${ }^{3}$ Davidson, J., Lallman, F., McMinn, J. D., Martin, J., Pahle, J., Stephenson, M., Selmon, J., and Bose, D., "Flight Control Laws for NASA's Hyper-X Research Vehicle," AIAA Guidance, Navigation, and Control Conference and Exhibit, Portland, OR, AIAA-99-4124, August 9-11, 1999.

${ }^{4}$ X-43A Mishap Investigation Board, "Report of Findings X-43A Mishap,” NASA, Washington, D.C., Vol. 1, May 8, 2003, also available@www.nasa.gov/pdf/47414main_x43A_mishap.pdf.

${ }^{5}$ McClinton, C. R., Rausch, V. L., Nguyen, L. T., and Sitz, J. R., "Preliminary X-43 Flight Test Results," IAC 04-V6-X43A 2.

${ }^{6}$ Davis, M. C., Pahle, J. W., White, J. T., Marshall, L. A., Mashburn, M. J., and Franks, R., Development of a Flush Airdata Sensing System on a Sharp-Nosed Vehicle for Flight at Mach 3 to 8, NASA-TM-2000-209017, 2000.

${ }^{7}$ Bosworth, J. T., and Burken, J. J., Tailored Excitation for Multivariable Stability-Margin Measurement Applied to the X-31A Nonlinear Simulation, NASA TM 113085, 1997. 